\title{
ANALISIS DE LA INSTITUCIONALIDAD AGROPECUARIA EN CHILE: UNA EXPERIENCIA A CONSIDERAR PARA VENEZUELA
}

CARLOS FURCHE 


\section{CONTENIDOS}

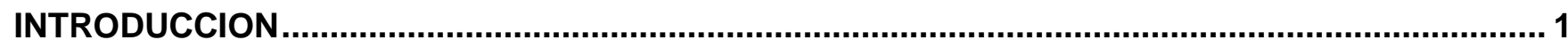

1. DESEMPEÑO GENERAL DEL SECTOR AGROALIMENTARIO. ........................................... 2

2. FACTORES QUE HAN IMPULSADO EL DESARROLLO SECTORIAL. ................................ 7

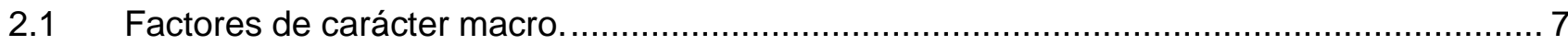

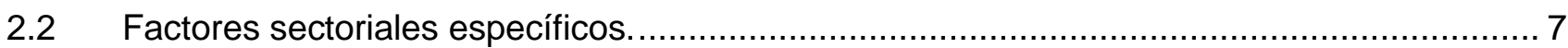

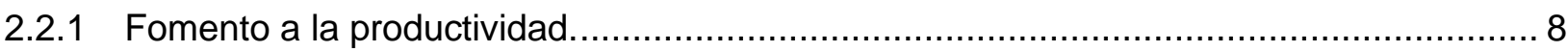

2.2.2 Apertura comercial gradual e inserción en los mercados globales............................. 8

2.2.3 Prioridad a la Agricultura Familiar Campesina. ................................................ 9

2.2.4 Incremento de estándares de sanidad e inocuidad. ............................................. 9

2.2.5 Sustentabilidad y adaptación al cambio climático. .......................................... 10

3. ESTRUCTURA INSTITUCIONAL DEL MINISTERIO DE AGRICULTURA............................11

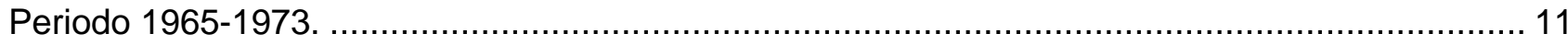

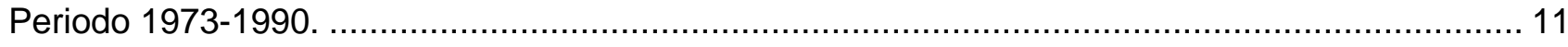

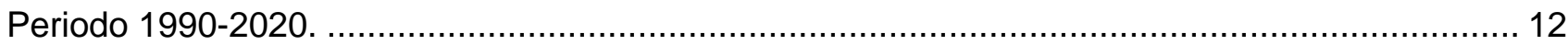

4. VINCULACION CON OTRAS AGENCIAS PUBLICAS. ....................................................... 14

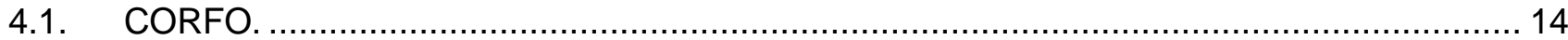

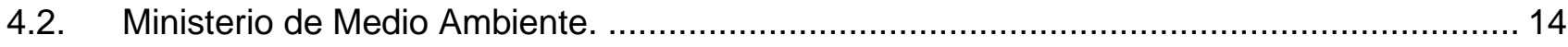

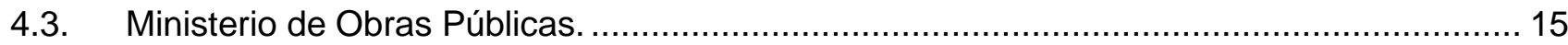

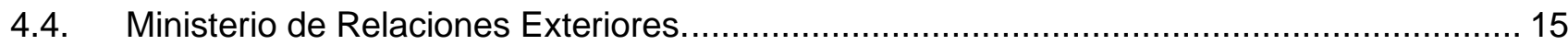

5. MARCO E INSTRUMENTOS LEGALES. ....................................................................... 16

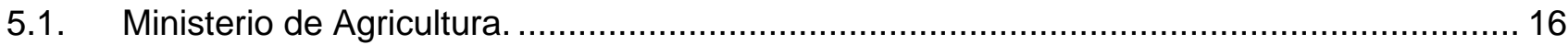

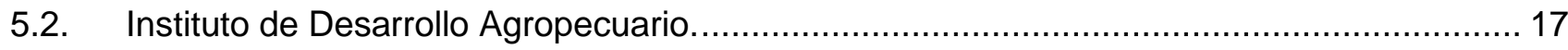

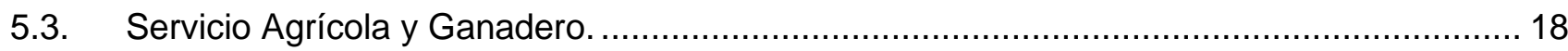

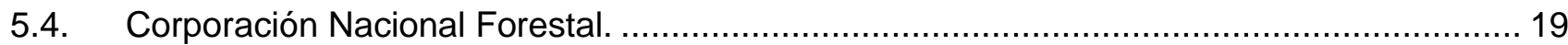

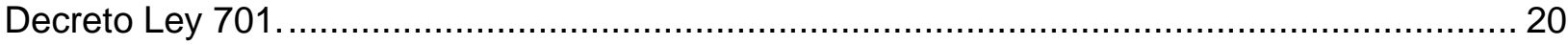

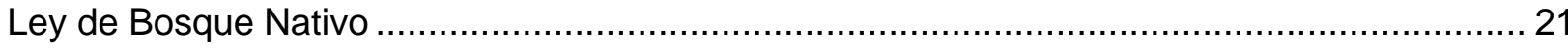

5.5. Oficina de Estudios y Políticas Agrarias. .......................................................... 21

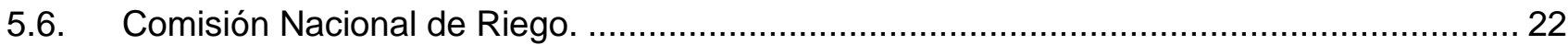




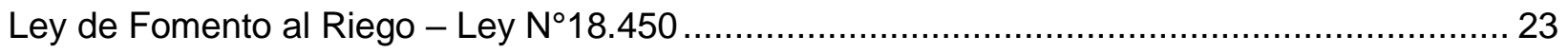

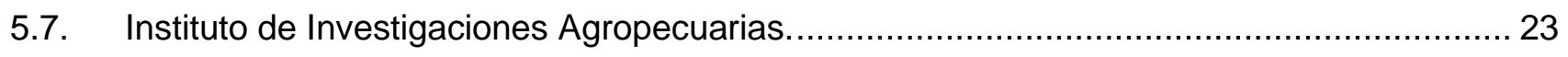

5.8. Centro de Información en Recursos Naturales.............................................................. 24

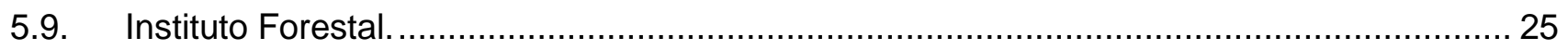

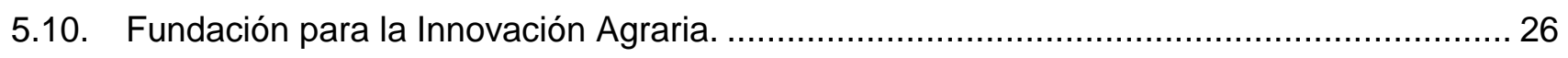

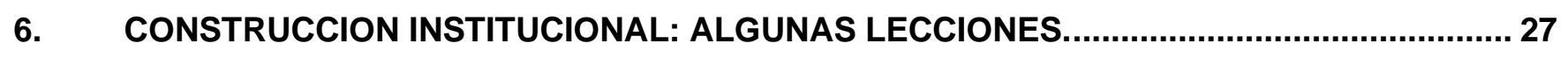

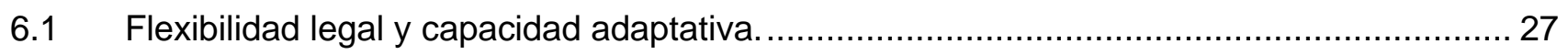

6.2 Funcionalidad a estrategia y objetivos de desarrollo sectorial. .......................................... 27

6.3 Articulación con institucionalidad pública de apoyo......................................................... 28

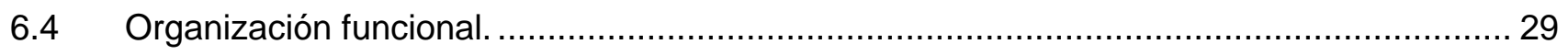

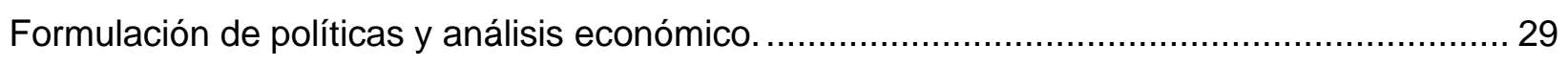

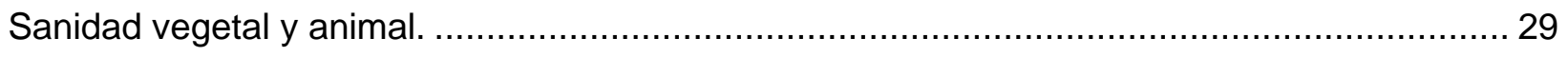

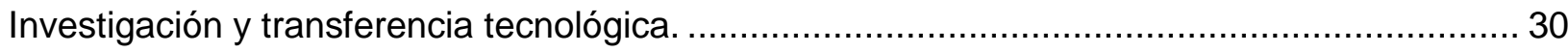

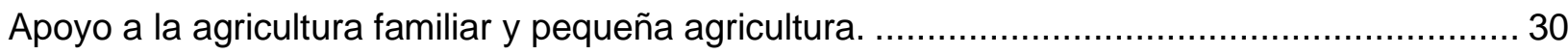

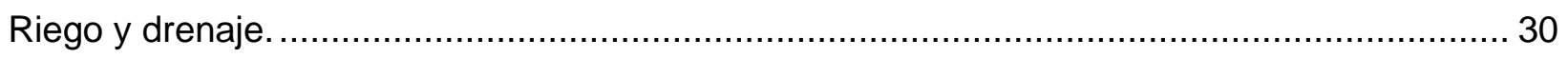

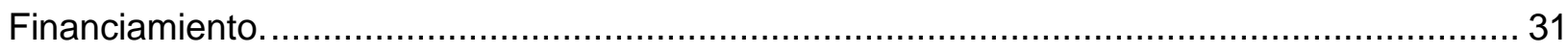

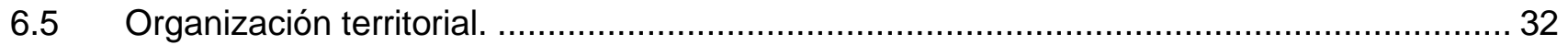

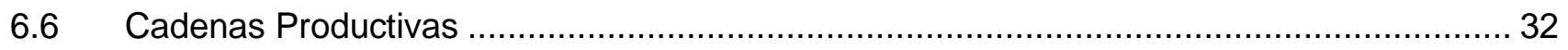

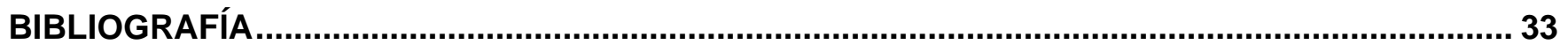

SOBRE EL AUTOR

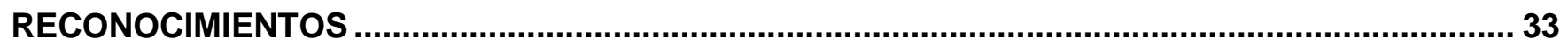

\section{CUADROS}

Cuadro 1. Balanza comercial de productos agropecuarios por sector. Chile - Mundo (miles de

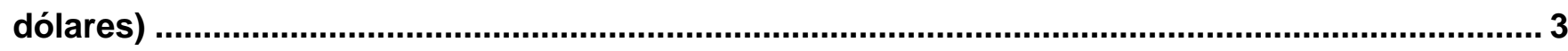

Cuadro 2. Estimacion de rendimientos de cultivos anuales …........................................................ 5

Cuadro 3. Organigrama Ministerio de Agricultura Chile ................................................................. 13 


\section{GRÁFICOS}

Gráfico 1. Evolucion de las exportaciones agropecuarias y forestales (US \$ 1.000)..................... 2

Gráfico 2. Evolución Superficie Fruticola (Hectareas) ................................................................4

Gráfico 3. Empleo Sector Silvoagropecuario (No. Personas)...................................................6 6

Gráfico 4. Destino de Exportaciones Agropecuarias y Forestal por Región Geográfica. año 2000

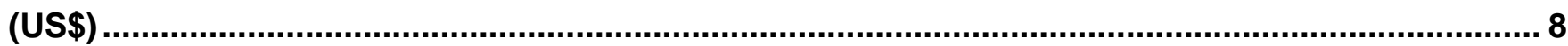

Gráfico 5. Destino de Exportaciones Agropecuarias y Forestal por Región Geográfica. Año 2019 (US\$). 


\section{SIGLAS Y ACRONIMOS.}

ACHIPIA: Agencia chilena para la inocuidad de los alimentos.

CIREN: Centro de información en recursos naturales

CNR: Comisión nacional de riego

CORFO: Corporación de Fomento de la Producción

CONAF: Corporación Nacional Forestal

FIA: $\quad$ Fundación para la innovación agraria

INDAP: Instituto de desarrollo agropecuaria.

INFOR: Instituto forestal

INIA: Instituto de Investigaciones Agropecuarias

ODEPA: Oficina de estudios y políticas agrarias.

SAG: Servicio agrícola y ganadero.

MINAGRI: Ministerio de Agricultura

MOP: $\quad$ Ministerio de Obras Publicas

SEREMI: secretarias regionales ministeriales 


\section{INTRODUCCION}

Este documento es parte del proyecto de IFPRI con Michigan State University (MSU) en apoyo a la recuperación del sistema agroalimentario en Venezuela. El objetivo de esta consultoría está relacionado con el componente siguiente del trabajo con MSU:

"3.2.3 Apoyar el proceso de reforma de las políticas, regulaciones e instituciones agroalimentarias de Venezuela involucradas. EI IFPRI, en colaboración con los técnicos de FEDEAGRO y PLAN PAIS, analizará la experiencia de países como Chile y Colombia en el diseño, aprobación e implementación de regulaciones y órdenes institucionales para apoyar la recuperación del sector agroalimentario. Esto también incluirá políticas comerciales y de mercado, así como leyes y reglamentos que apoyen el sector de préstamos agroalimentarios."

Este documento se enfoca en la experiencia sobre leyes, políticas, regulaciones e instituciones en Chile, y las posibles lecciones para Venezuela. Se considera que la experiencia chilena es útil, entre otras razones, por ser una economía en la que el sector agropecuario, como en el caso de Venezuela, ha tenido que funcionar en una matriz productiva con un producto mineral dominante (cobre en el caso de Chile) que genera condiciones de "Enfermedad Holandesa" en el resto de los sectores comercializables. Este trabajo, está dividido en las siguientes secciones. La primera describe brevemente el desempeño del sector agropecuario chileno, como antecedente para el análisis institucional y de políticas. La segunda sección discute una variedad de factores que han impulsado el desarrollo sectorial, separando los aspectos macroeconómicos de los específicos de políticas e instituciones sectoriales. La tercera sección discute la estructura institucional del Ministerio de Agricultura de Chile. La cuarta sección analiza las vinculaciones con otras agencias e instituciones públicas con actividades relacionadas con el sector agropecuario. La quinta sección presenta el marco y los instrumentos legales (los documentos completos se adjuntan en Anexos). Finalmente, la última sección discute lecciones sobre la construcción institucional que se consideran relevantes para el caso de Venezuela. 


\section{DESEMPEÑO GENERAL DEL SECTOR AGROALIMENTARIO.}

La revisión de las principales variables del comportamiento del sector agroalimentario durante los últimos 20 años permite apreciar que este se ha sustentado en un conjunto diverso de condiciones, entre las cuales han jugado un rol significativo las políticas públicas y la consistencia y funcionalidad de las instituciones estatales, particularmente las del Ministerio de Agricultura.

El sector agroalimentario chileno ha mostrado un crecimiento sostenido durante las ultimas décadas, lo que se refleja en algunos de sus indicadores más relevantes, entre ellos valor y volumen de las exportaciones, empleo y productividad, uso del suelo y reducción de la pobreza.

En efecto, el valor de las exportaciones creció en los últimos 20 años desde US\$ 3.000 millones a US\$ 15.700 millones, diversificando su canasta de bienes exportables, sus mercados de destino y ampliando la frontera geográfica y agroecológica para la agricultura de exportación. ${ }^{1}$

Gráfico 1. Evolucion de las exportaciones agropecuarias y forestales (US \$1.000)

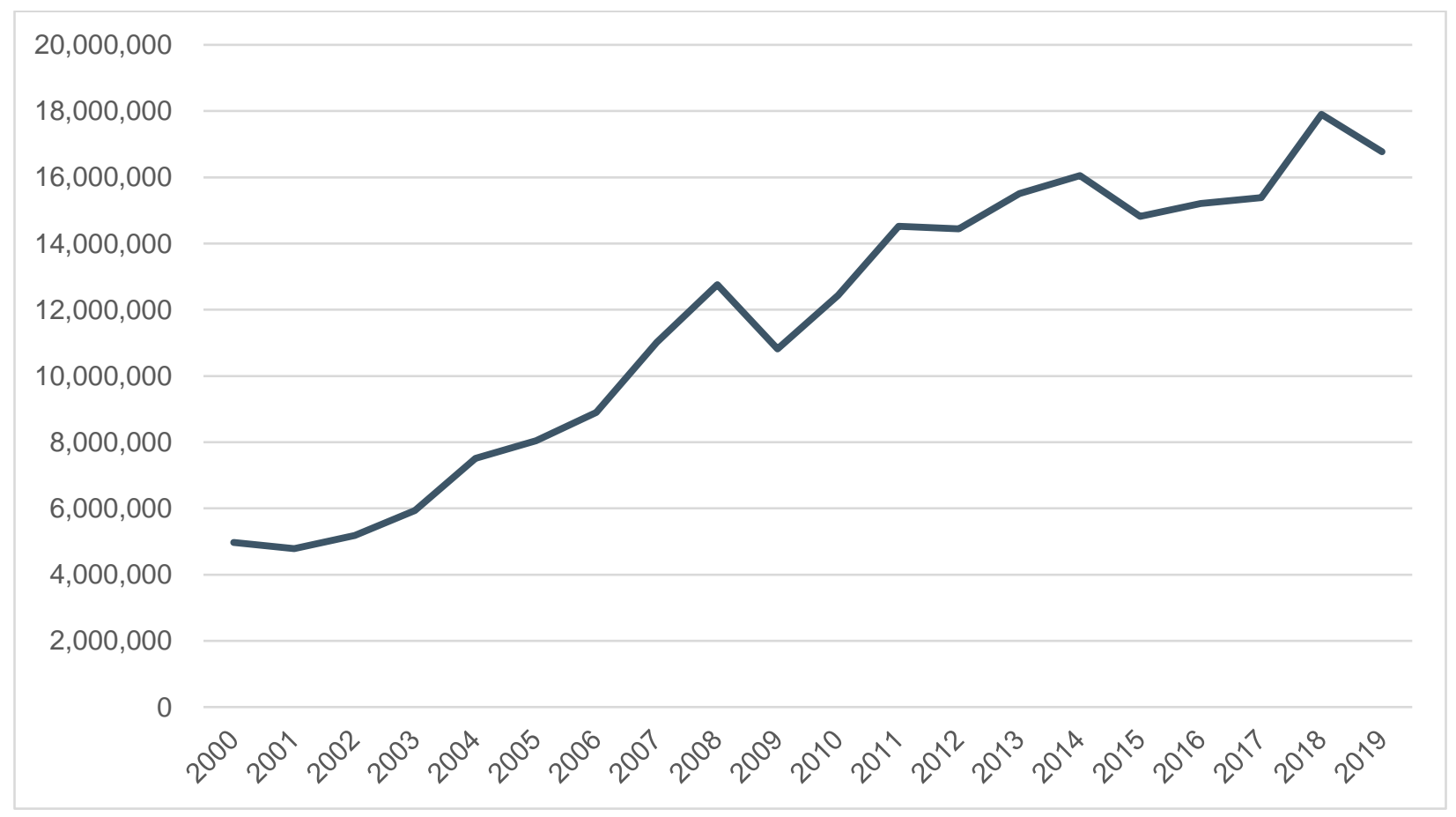

Fuente: Elaboración propia en base datos ODEPA

Esta expansión acelerada posicionó al sector como el segundo en importancia luego de la minería esencialmente cuprífera, y convirtió al sector agropecuario y forestal en ampliamente superavitario desde el punto de vista de la balanza comercial.

\footnotetext{
${ }^{1}$ Odepa. Ministerio de Agricultura. Santiago, diciembre 2019.
} 
Cuadro 1. Balanza comercial de productos agropecuarios por sector. Chile - Mundo (miles de dólares)

\begin{tabular}{|c|c|c|c|c|c|c|}
\hline sector & $\begin{array}{c}2018 \\
\text { ene-dic }\end{array}$ & $\begin{array}{c}2019 \\
\text { ene-dic }\end{array}$ & $\begin{array}{c}2019 \\
\text { ene-mar }\end{array}$ & $\begin{array}{c}2020 \\
\text { ene-mar }\end{array}$ & $\begin{array}{c}\text { Variación } \\
\text { 2020-2019 }\end{array}$ & Participación \\
\hline \multicolumn{7}{|c|}{ Exportaciones por sector } \\
\hline Total silvoagropecuario & 17.900 .894 & 16.739 .027 & 5.343 .606 & 4.451 .284 & $-16,7 \%$ & \\
\hline Agricola & 10.212 .555 & 10.238 .132 & 3.595 .711 & 3.056 .655 & $-15,0 \%$ & $68,7 \%$ \\
\hline Pecuario & 1.380 .778 & 1.458 .680 & 339.813 & 407.773 & $20,0 \%$ & $9,2 \%$ \\
\hline Forestal & 6.307 .561 & 5.042 .215 & 1.408 .082 & 986.856 & $-29,9 \%$ & $22,2 \%$ \\
\hline \multicolumn{7}{|c|}{ Importaciones por sector } \\
\hline Total silvoagropecuario & 6.559 .563 & 6.347 .232 & 1.529 .656 & 1.583 .305 & $3,5 \%$ & \\
\hline Agricola & 4.085 .369 & 3.946 .637 & 987.562 & 998.352 & $1,1 \%$ & $63,1 \%$ \\
\hline Pecuario & 2.142 .767 & 2.140 .515 & 472.970 & 531.201 & $12,3 \%$ & $33,6 \%$ \\
\hline Forestal & 331.427 & 260.080 & 69.124 & 53.752 & $-22,2 \%$ & $3,4 \%$ \\
\hline \multicolumn{7}{|c|}{ Balanza comercial de productos } \\
\hline Total silvoagropecuario & 11.341 .331 & 10.391 .795 & 3.813 .950 & 2.867 .979 & $-24,8 \%$ & \\
\hline Agricola & 6.127 .186 & 6.291 .495 & 2.608 .149 & 2.058 .303 & $-21,1 \%$ & $71,8 \%$ \\
\hline Pecuario & -761.989 & -681.835 & -133.157 & -123.428 & $\%$ & $\%$ \\
\hline Forestal & 5.976 .134 & 4.782 .135 & 1.338 .958 & 933.104 & $-30,3 \%$ & $32,5 \%$ \\
\hline
\end{tabular}

Fuente: elaborado por OEPA con información del Servicio Nacional de Aduanas. Nota: Cifras sujetas a revisión por informes de variación de valor (IVV).

Sin duda la expansión de un tipo de agricultura mas intensiva en el uso de los factores, cuya principal expresión es el aumento y diversificación de la superficie destinada a la producción frutícola, a lo que puede agregarse el crecimiento en las plantaciones de viñas vitícolas y de la industria vinícola en general, la producción de semillas de exportación, la floricultura y también el sector forestal con la expansión de especies exóticas y el desarrollo de una potente industria procesadora han sido motores para la atracción de tecnología, inversiones y modernas prácticas de gestión que han impactado al conjunto del sector.

El aumento de la superficie frutícola desde poco menos de 200.000 has el año 2.000 a casi 350.000 has dos décadas después, indica una expansión acelerada, siendo destacable por una parte la incorporación de nuevas especies, como cerezas que en cinco años se ha transformado en el principal rubro de exportación o nueces y almendras que igualmente muestran un crecimiento muy dinámico. Debe destacarse igualmente, la expansión de la fruticultura hacia nuevos espacios agroecológicos, lo que es una respuesta de adaptación productiva al cambio climático que ha favorecido ese proceso y también un indicador de inversión e innovación tecnológica. ${ }^{2}$

\footnotetext{
${ }^{2}$ En años recientes la fruticultura se ha expandido hacia el sur del país, introduciendo especies tales como cerezos, arándanos, avellano europeo y otros.
} 
Gráfico 2. Evolución Superficie Fruticola (Hectareas)

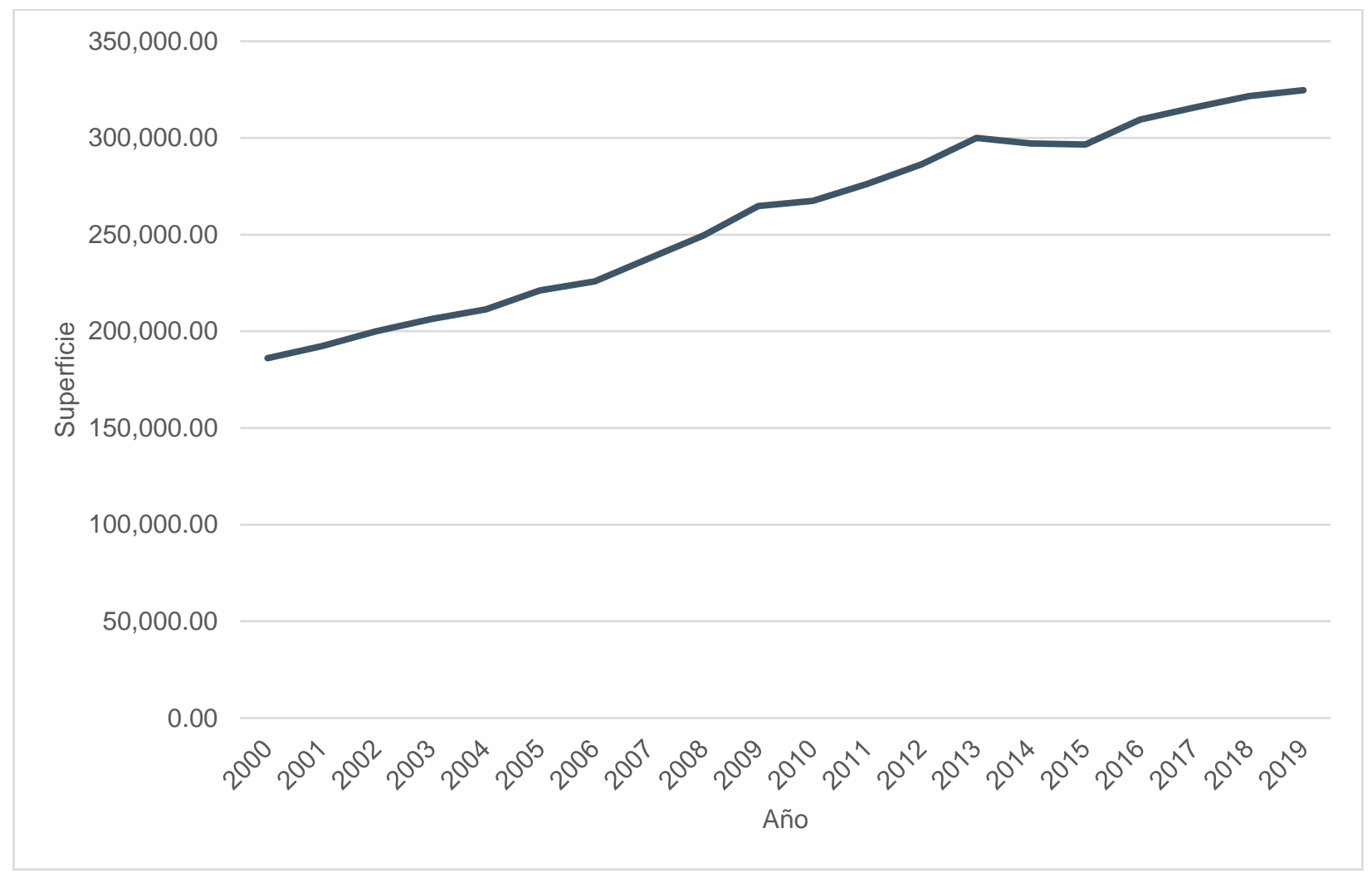

Fuente: Elaboración propia en base a datos CIREN-ODEPA

A las plantaciones frutícolas debe adicionarse una superficie estimada de 120.000 has destinada a viñedos vinícolas, de manera que la superficie destinada a agricultura intensiva se acerca al medio millón de has.

Por otra parte, la producción de aves y cerdos se ha articulado a la oferta chilena de alimentos, de modo que, junto a otros rubros como ovinos, bovinos e incluso lácteos, alcanzan casi US \$1.500 millones de dólares de exportaciones.

En lo que se refiere a los rubros sustituidores de importaciones, especialmente granos, oleaginosas, arroz y azúcar, si bien se aprecia una disminución gradual de las superficies sembradas, los volúmenes de producción local se han mantenido bastante estables por la incorporación de tecnologías que han permitido aumentar sus rendimientos por ha, como se aprecia en el gráfico siguiente, que muestran aumentos significativos de rendimientos para los principales cultivos anuales. ${ }^{3}$

Es relevante consignar que la disminución de las superficies sembradas generalmente obedece a su reemplazo por producciones más rentables, tanto en la fruticultura como en la ganadería, e incluso en cultivos anuales como avena, raps, chicoria y otros.

\footnotetext{
${ }^{3}$ La superficie sembrada con cultivos anuales ha disminuido en torno al $35 \%$ durante la ultima década, destacando la caída en la superficie de trigo, maíz, arroz y remolacha.
} 
Cuadro 2. Estimacion de rendimientos de cultivos anuales

\begin{tabular}{|c|c|c|c|}
\hline \multicolumn{4}{|c|}{ Rendimiento (qqm/hectareas) } \\
\hline Cultivo & $2000 / 2001$ & 2018/2019 & Variación \% \\
\hline Trigo & 43,0 & 62,9 & 46,2 \\
\hline Trigo Harinero & $s / i$ & 61,7 & \\
\hline Trigo Candeal & $s / i$ & 71,4 & \\
\hline Avena & 38,4 & 51,6 & 34,4 \\
\hline Maíz & 94,3 & 121,0 & \\
\hline Maíz Consumo & $s / i$ & 128,8 & \\
\hline Maíz Semilla & $s / i$ & 33,6 & \\
\hline Arroz & 50,2 & 66,6 & 32,6 \\
\hline Raps* & 29,5 & 38,5 & 30,5 \\
\hline
\end{tabular}

*Incluye semilleros

Fuente: Elaboración propia en base datos ODEPA

Es destacable igualmente el comportamiento del empleo agrícola estabilizado en los últimos años en torno al $8 \%$ o $9 \%$ de la fuerza de trabajo total. Ello en un proceso en que la producción agropecuaria ha aumentado de modo muy significativo, de manera que la productividad sectorial, aún cuando es más baja que en otros sectores, como minería o servicios, registra un aumento superior al promedio de crecimiento de la productividad general de la economía. ${ }^{4}$

\footnotetext{
${ }^{4}$ Aproximadamente dos tercios de la fuerza de trabajo ocupada en la agricultura se emplea en la fruticultura y viñas.
} 
Gráfico 3. Empleo Sector Silvoagropecuario (No. Personas)

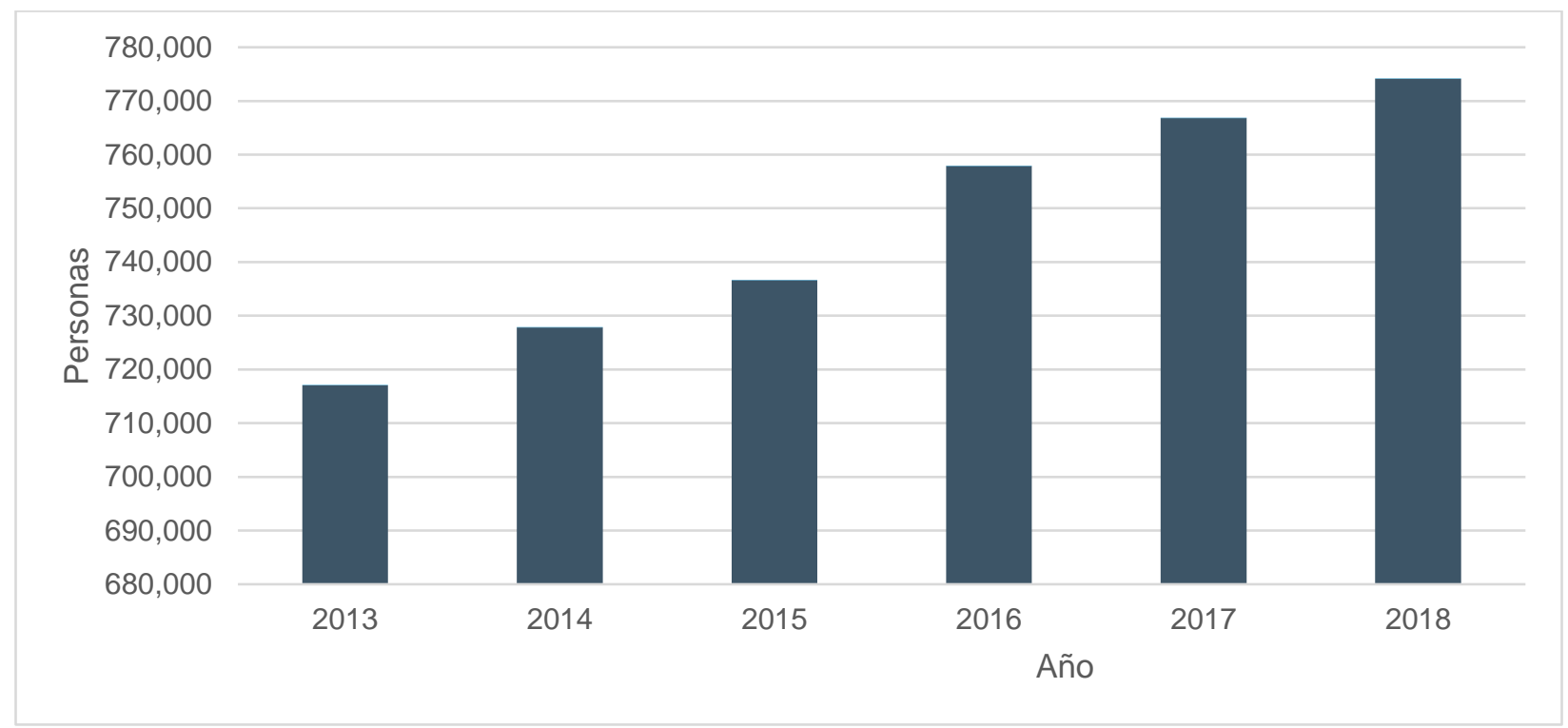

Fuente: Elaboración propia en base datos ODEPA

Por otra parte, los índices de pobreza rural también han disminuido significativamente, cayendo desde poco más de 50\% en el año 2006 a 16.5\% en 2017. Esta caída obedece tanto al crecimiento dinámico del sector reflejado en salarios e ingresos, como también por las transferencias directas canalizadas a través de municipios y otras agencias públicas. 


\section{FACTORES QUE HAN IMPULSADO EL DESARROLLO SECTORIAL.}

Un análisis somero acerca de los principales factores que han favorecido e impulsado esta exitosa inserción en los mercados internacionales permite identificar tanto razones vinculadas al manejo macroeconómico y estabilidad política e institucional de Chile durante las últimas tres décadas, como a aspectos específicos de política agrícola igualmente caracterizada por su continuidad temporal.

\subsection{Factores de carácter macro.}

Como se ha señalado, el positivo desempeño del sector agroalimentario ha ocurrido en el contexto de un ambiente macroeconómico y político favorable a la inversión, en un marco de activa cooperación público/privada y con la puesta en operación de políticas orientadas a propiciar la inclusión social. Esto último se refleja en numerosos indicadores, particularmente en la significativa reducción de la pobreza urbana y rural, desde niveles superiores al 40\% en 1990 hasta tasas inferiores al 10\% en 2019.

Entre los factores y condicionantes macros de mayor relevancia para la actividad productiva del sector agroalimentario pueden destacarse entre otros:

a. Marcada estabilidad política y económica, con un manejo ampliamente consensuado de las principales variables macroeconómicas, especialmente la política fiscal y cambiaria, así como ajuste gradual de la carga tributaria para financiar políticas de cohesión e inclusión social.

b. Impulso a un proceso gradual de apertura de la economía, mediante la reducción de aranceles desde un nivel de $30 \%$ en 1990 hasta el actual de 6\%, que, en la práctica en función de los acuerdos comerciales, se sitúa en torno al $1 \%$.

c. La negociación de acuerdos comerciales y tratados de libre comercio (TLCs), lo que ha permitido a la economía chilena un acceso preferente para el $90 \%$ de sus exportaciones a los principales mercados globales.

d. Estabilidad en las reglas, particularmente en lo relacionado con la propiedad de la tierra, independencia de los poderes del Estado y cumplimento de la ley.

\subsection{Factores sectoriales específicos.}

Durante un periodo prolongado de tiempo, poco más de dos décadas, se ha mantenido una estrategia de desarrollo sectorial de amplio consenso público y privado sobre la base de definiciones que han determinado las políticas e instrumentos puestas en operación. Los pilares de dicha estrategia han sido principalmente: ${ }^{5}$

\footnotetext{
${ }^{5}$ El documento: Una política de estado para la agricultura chilena, periodo 2000-2010, sienta bases mantenidas en buena medida hasta la actualidad, y que en su oportunidad fueron construida con un proceso amplio de participación publica y privada.
} 


\subsubsection{Fomento a la productividad.}

El retiro gradual de políticas de protección en frontera (bandas de precios) para algunos productos básicos, fue reemplazado por instrumentos de apoyo a la productividad, particularmente mejoras en calidad y productividad de suelos y recursos para riego y drenaje.

\subsubsection{Apertura comercial gradual e inserción en los mercados globales.}

La negociación de los tratados de libre comercio y la disminución ${ }^{6}$ unilateral de aranceles ha significado una casi total apertura del sector. Ello se pactó con los sectores afectados, de manera de disponer de un periodo de ajuste y adaptación que para los productos más sensibles alcanzó entre 15 y 18 años.

En paralelo, el apoyo a la apertura de mercados y promoción comercial han favorecido la conquista de mercados diversificados, principalmente en Asia, Europa y América del Norte.

En efecto, como se aprecia en los gráficos siguientes, en el transcurso de los últimos 20 años, la importancia relativa de Asia como destino de las exportaciones sectoriales se ha duplicado, pasando de $21 \%$ a $42 \%$, en tanto Europa y América del Norte han disminuido en términos relativos, todo ello en un contexto de un gran aumento general del valor total de las exportaciones del sector agropecuario y forestal.

Gráfico 4. Destino de Exportaciones Agropecuarias y Forestal por Región Geográfica. año 2000 (US\$)

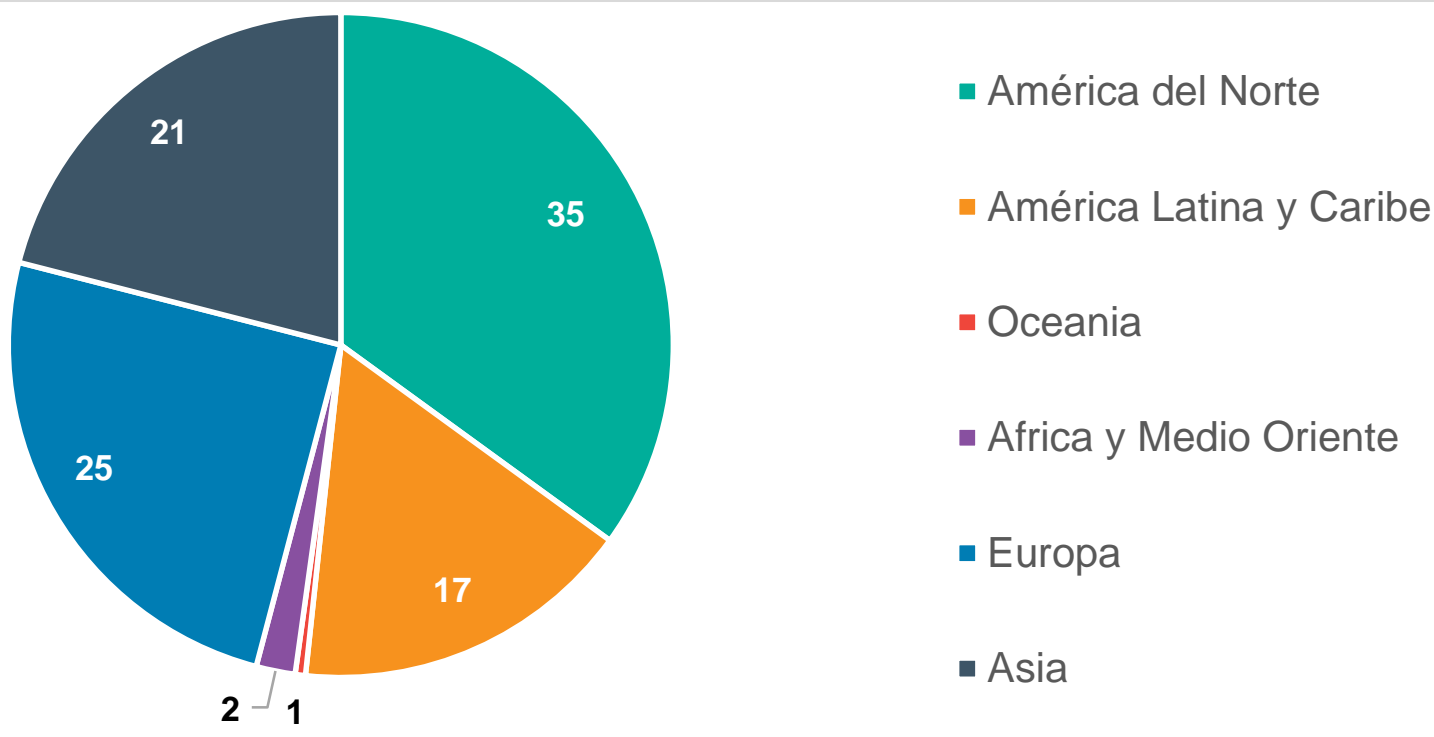

Fuente: Elaboración propia en base datos ODEPA

\footnotetext{
${ }^{6}$ En los últimos años, China se ha convertido en el principal destino de las exportaciones de alimentos, desplazando a Estados Unidos al segundo lugar. Un ejemplo particular es el mercado de las cerezas, China importa a el $90 \%$ del total de los envíos chilenos de esa fruta.
} 
Gráfico 5. Destino de Exportaciones Agropecuarias y Forestal por Región Geográfica. Año 2019 (US\$)

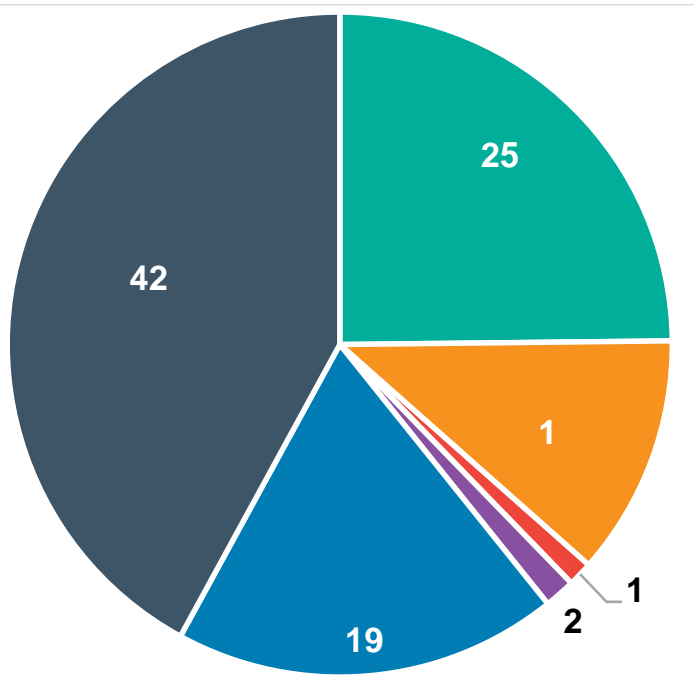

- América del Norte

- América Latina y Caribe

- Oceania

- Africa y Medio Oriente

- Europa

- Asia

Fuente: Elaboración propia en base datos ODEPA

Los tratados de libre comercio han jugado un rol decisivo en este cambio en los mercados de destino, en especial aquellos negociados con China, Japón y Corea, así como con algunas de las principales economías de ASEAN.

\subsubsection{Prioridad a la Agricultura Familiar Campesina.}

En Chile se estima la existencia de poco más de 300 mil explotaciones agropecuarias, de las cuales más del $80 \%$ corresponden a pequeña y mediana agricultura. ${ }^{7}$ En el caso de la pequeña agricultura, se destaca que una parte muy significativa del abastecimiento de alimentos frescos de consumo cotidiano, como frutas y hortalizas distribuidas a través de ferias locales y supermercados, tienen origen en la agricultura campesina. ${ }^{8}$

Esta prioridad se refleja en que una parte muy significativa de los recursos asignados al Ministerio de Agricultura, aproximadamente $50 \%$ del total, se ejecutan a través del Instituto de Desarrollo Agropecuario (INDAP) que torga crédito y apoyo técnico a la agricultura campesina de acuerdo a lo que establece su marco legal.

\subsubsection{Incremento de estándares de sanidad e inocuidad.}

La eliminación de plagas y enfermedades cuarentenarias, así como la protección en frontera y la negociación de protocolos de acceso a mercados en los principales mercados de destino ha sido otro eje

\footnotetext{
${ }^{7}$ De acuerdo a Odepa: Panorama de la agricultura chilena 2019, el 58,4\% de las propiedades se ubica en el rango de hasta 10 has, en tanto en el rango de hasta 50 has se encuentra el $86 \%$ de las propiedades.

${ }^{8}$ Estimaciones de ODEPA, que seguramente serán actualizadas luego de la realización del Censo Nacional Agropecuario previsto para este año.
} 
estratégico, que ha permitido especialmente a la agricultura de exportación un acceso casi ilimitado a los mercados externos.

\subsubsection{Sustentabilidad y adaptación al cambio climático.}

En años recientes se ha tornado muy evidente el impacto del cambio climático. Sequías extensas y prolongadas, heladas fuera de sus temporadas normales, y en general cambios en el comportamiento de las principales variables del clima se han transformado en el principal desafío de la agricultura chilena. La construcción de infraestructura de riego, el estímulo a sistemas productivos más amigables con el medio ambiente y la incorporación de tecnologías que mejoren la adaptabilidad de los cultivos son elementos crecientemente importantes de la estrategia sectorial.

Junto a los señalados factores de carácter macro, son destacables varios que corresponden más específicamente a políticas sectoriales sostenidas durante un periodo prolongado de tiempo, sin perjuicio de ajustes y revisiones periódicas.

a. Las políticas de apertura comercial a través de TLC s con las principales economías del mundo que hicieron posible valorizar las características naturales del país, con su agricultura de clima mediterráneo y de contra estación con los países desarrollados del hemisferio norte.

b. La puesta en operación de instrumentos de fomento productivo, tales como riego, mejoramiento de suelos, investigación y transferencia tecnológica, modernización de la gestión y apoyo a la organización de pequeños productores entre otros, de modo de favorecer su adaptación al escenario de apertura comercial.

c. La sostenida política de mejoramiento de las condiciones fito y zoosanitarias, eliminando prácticamente todas las plagas y enfermedades de carácter cuarentenario que limitan o impiden el comercio internacional, y el establecimiento de sistemas de trazabilidad animal y vegetal acordes con las exigencias de los diversos mercados internacionales.

d. El establecimiento de mecanismos de fomento a la innovación tecnológica, mediante la acción de la Corporación de Fomento de la Producción (CORFO) y la creación de la Fundación para la Innovación Agraria (FIA).

e. El fortalecimiento y ampliación de los servicios del Instituto de Desarrollo Agropecuario (INDAP) orientado al apoyo técnico, organizacional y financiero de la pequeña agricultura y el aumento de los recursos para riego y drenaje, a través de la Comisión Nacional de Riego (CNR).

f. La descentralización y especialización regional del Instituto de Investigaciones Agropecuarias (INIA) procurando focalizar su investigación en función a los desafíos tecnológicos adecuados a las diferentes realidades agroecológicas del país. 


\section{ESTRUCTURA INSTITUCIONAL DEL MINISTERIO DE AGRICULTURA.}

Como ocurre generalmente, las estructuras institucionales del sector público son el producto de procesos sucesivos de ajustes funcionales, legales y normativos, que a su vez reflejan los cambios en el escenario global y nacional, así como los ajustes en las prioridades en el desarrollo económico del país y también en los desafíos propios de la agricultura y la alimentación.

La creación del Ministerio de Agricultura en Chile se remonta al año 1924 y desde esa fecha ha sufrido diversos ajustes tanto en su estructura administrativa como en el marco legal que le da sustento a su funcionamiento. Los periodos o momentos más relevantes de ajuste institucional que vale la pena destacar son los siguientes:

\section{Periodo 1965-1973.}

En dicho periodo la agenda sectorial estaba dominada por una parte por el proceso de reforma agraria, y por otro por el esfuerzo de valorizar las condiciones naturales para la expansión de la fruticultura, la ganadería y el desarrollo forestal.

Ello dio origen a la creación de la Corporación de Reforma Agraria, CORA, responsable por el proceso de restructuración fundiaria puesto en marcha en la época. Igualmente, se creó la Oficina de Planificación Agrícola, ODEPA, responsable por la preparación de los planes y programas con que se buscaba orientar el desarrollo sectorial, y al mismo tiempo ser el organismo técnico para informar los instrumentos de fijación de precios, administración de stocks de insumos y productos y en general la activa intervención estatal en el desarrollo sectorial.

Igualmente, se transformó y descentralizó la Dirección General de Agricultura, de amplio mandato, dando origen al organismo especializado en el control fito y zoo sanitario, Servicio Agrícola y Ganadero (SAG), al Instituto de Desarrollo Agropecuario (INDAP) a la Corporación Nacional Forestal (CONAF) y al Instituto de Investigaciones Agropecuarias (INIA).

En 1970 se creó la Corporación Nacional Forestal, CONAF, con la finalidad de promover el potencial de desarrollo forestal asociado a las plantaciones de especies exóticas, tales como pino y eucalipto que han sido la base para la generación de una potente industria vinculada al procesamiento e industrialización de sus productos. ${ }^{9}$

\section{Periodo 1973-1990.}

Corresponde al periodo autoritario regido por un gobierno militar, que puso tempranamente entre sus prioridades la paralización y reversión del proceso de reforma agraria, la liberalización parcial de la economía y el retiro de varios de los instrumentos de política sectorial de la época, como la fijación de precios, cuotas de importación y administración de stocks de productos básicos.

\footnotetext{
${ }^{9}$ Las plantaciones forestales de pino y eucalipto alcanzan a 2.8 millones de has, en tanto la superficie cubierta con diversas especies de bosque nativo supera los 13 millones de has. Igualmente, CONAF es responsable del cuidad y administración de los parques nacionales que abarcan extensas extensiones del país, especialmente en la Patagonia sur y austral.
} 
Desde el punto de vista institucional ello se tradujo en el término de la CORA, y posteriormente en la disolución de ODEPA como organismo de planificación. Igualmente, se procedió a una privatización parcial del INIA y a una reducción significativa de recursos y atribuciones de INDAP.

\section{Periodo 1990-2020.}

Una vez reiniciados los gobiernos democráticos a partir de 1990, nuevamente las prioridades desde el punto de vista económico y social cambian significativamente, lo que origina ajustes en la estructura institucional del MINAGRI. Entre los más importantes pueden destacarse:

La creación de la Oficina de Estudios y Políticas Agrarias, ODEPA, que si bien contempla su sigla original, recibe un mandato adaptado a las nuevas prioridades, concentrando su accionar en estudios económicos y sociales, generación de información relevante para los agentes públicos y privados, apoyo a las negociaciones comerciales internacionales y funciones de secretaría técnica en las diversas instancias de gobernanza sectorial, públicas y público/privada que requieren participación y decisión de parte de las autoridades del MINAGRI.

Se crea igualmente la Fundación para la Innovación Agraria, FIA, destinada a fomentar, mediante capital de riesgo, la introducción de innovaciones a lo largo de las cadenas productivas y la búsqueda de nuevos productos y alternativas productivas.

El fortalecimiento de las funciones del SAG, ampliando sus funciones nacionales e internacionales como eje fundamental del proceso de apertura de la economía agrícola. Igualmente, se le asignaron atribuciones en lo referido a sustentabilidad y medio ambiente y al establecimiento y control de sistemas de trazabilidad de la producción agrícola y pecuaria.

Fortalecimiento de las capacidades técnicas y presupuestarias del INDAP, como organismo encargado de materializar la prioridad asignada al fomento de la agricultura familiar y campesina. De hecho, este servicio pasó a administrar el 50\% del presupuesto total del MINAGRI, ampliando su cobertura y diversificando su accionar apoyando no solo la disponibilidad de capital de operaciones sino también recursos para inversión especialmente proyectos con componentes de asociatividad.

La ampliación de recursos y atribuciones de la Comisión Nacional de Riego, trasladando su dependencia desde el Ministerio de Economía al MINAGRI, expandiendo su cobertura geográfica y aumentando de modo significativo el presupuesto destinado al fomento del riego y drenaje como sustento de una agricultura y ganadería más intensiva.

Traslado de la dependencia del Centro de Investigación en Recursos Naturales, CIREN, desde la Corporación de Fomento (CORFO) a MINAGRI, atendiendo a las necesidades de recoger y sistematizar información respecto al estado y evolución de los recursos naturales vinculados a la producción agroalimentaria.

Se comenzó igualmente un proceso destinado a institucionalizar las obligaciones y atribuciones en materia de inocuidad de los alimentos, enviando al congreso nacional un proyecto de ley que transforma en servicio público la Agencia Chilena para la Inocuidad de los Alimentos, con dependencia en MINAGRI y corresponsabilidad en dirección y decisiones con el Ministerio de Salud. 
Cuadro 3. Organigrama Ministerio de Agricultura Chile

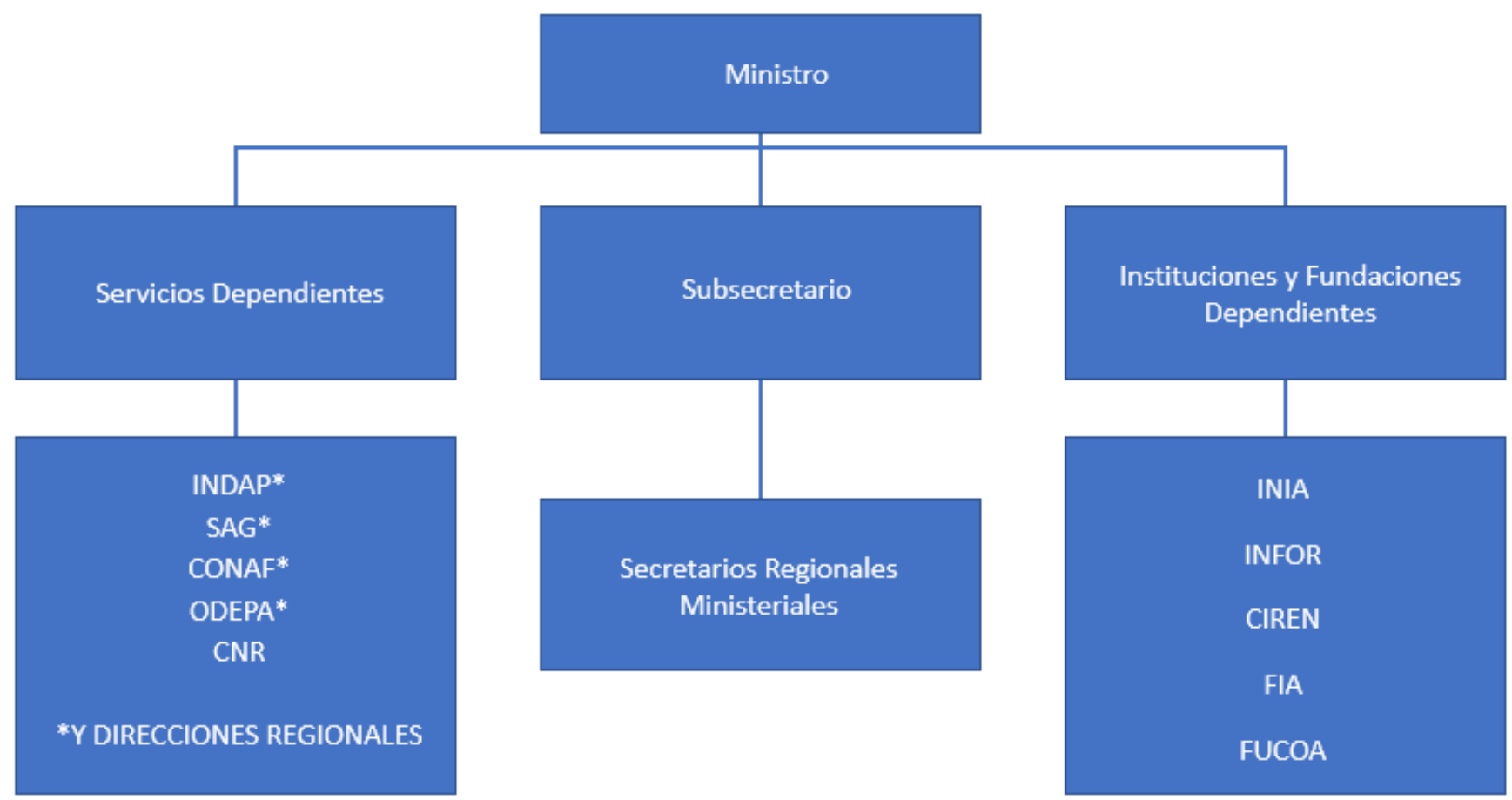

Fuente: Elaboración Propia para fines de este estudio - 2020

Los ajustes a la estructura institucional de los últimos años, a pesar de que se observan todavía rigideces y necesidades de ajuste, son un buen reflejo de la necesidad de concebir las estructuras institucionales de un modo dinámico, que sin duda requerirá de ajustes que acompañen las necesidades de la realidad global y sectorial. ${ }^{10}$

Por otra parte, la ampliación y complejizacion de los sistemas alimentarios, demanda una articulación cada vez más estrecha con otras agencias y servicios públicos, cuya acción y normativas poseen un amplio impacto sobre el sector agropecuario y forestal.

\footnotetext{
${ }^{10}$ Durante los primeros meses del presente año, el Gobierno envió al Congreso un proyecto de ley que modifica la conformación del Ministerio de Agricultura, trasladando a su dependencia la Subsecretaría de Pesca en la actualidad dependiente del Ministerio de Economía, y ampliando las atribuciones del Ministerio de un modo amplio a la alimentación.
} 


\section{VINCULACION CON OTRAS AGENCIAS PUBLICAS.}

La heterogeneidad del sector agropecuario, y la complejidad creciente de los sistemas agroalimentarios, determina la necesidad de articularse con otras agencias públicas que tanto desde el punto de vista normativo como desde los recursos que inyectan al sector a través de diferentes programas, son cada vez más significativos para el desempeño sectorial. Entre los principales entes públicos con los cuales se ha formalizado esta articulación institucional pueden destacarse los siguientes. ${ }^{11}$

\subsection{CORFO.}

La Corporación de Fomento, CORFO, creada en Chile a fines de la década del 1930, ha jugado un rol muy relevante desde su creación, en el impulso a políticas de fomento productivo orientadas a diversos sectores de la economía, y más recientemente a la promoción de innovaciones tecnológicas e impulso a la conformación de clusters productivos capaces de agregar valor a la producción nacional.

En el caso del sector agropecuario, deben destacarse el impulso a los programas de modernización de la gestión, los programas para el desarrollo de alimentos funcionales, los clusters frutícola, vitivinícola y ganadero entre otros.

Igualmente, la gran flexibilidad de su marco legal, ha permitido a CORFO el establecimiento de programas de estímulo y facilitación de financiamiento a través del sistema financiero, por ejemplo, con la creación del Fondo de Garantías al Pequeño Empresario (FOGAPE), o el respaldo al establecimiento de líneas de financiamiento para recuperación y transformación productiva. En definitiva, la acción de CORFO adquiere especial relevancia para la agricultura de tamaño mediano, que no puede ser apoyada directamente a través de INDAP dependiente del MINAGRI. ${ }^{12}$

Las directrices estratégicas y la definición de sus principales programas deben ser aprobadas por un Consejo de Ministros, del que forma parte el Ministro de Agricultura, junto a los Ministros de Economía, Hacienda, Relaciones Exteriores, así como algunos representantes del sector privado.

\subsection{Ministerio de Medio Ambiente.}

La importancia creciente en la agenda pública y en la preocupación ciudadana de los temas medioambientales, han ido aumentando también la relevancia institucional del Ministerio de Medio Ambiente, como la entidad responsable por la elaboración de políticas y programas orientadas a la preservación del medio ambiente, frecuentemente estableciendo limitaciones y condiciones al desarrollo de otras actividades productivas.

Naturalmente la interacción entre el Ministerio de Medio Ambiente y el de Agricultura es de gran relevancia y sensibilidad, atendiendo al hecho de que la producción agropecuaria y forestal ha intervenido e interviene activamente sobre los ecosistemas naturales.

\footnotetext{
${ }^{11}$ De manera análoga a la complejizacion de la agricultura dando lugar a sistemas agroalimentarios, se hace necesario coordinar y articular un sector publico ampliado, que excede competencias y atribuciones de los ministerios de agricultura, pero cuya acción tiene significativos impactos sectoriales.

${ }^{12}$ La flexibilidad del marco legal de CORFO le ha permitido mediante decisiones administrativas generar institucionalidad liviana, para abordar emergencias y catástrofes naturales, o temas estructurales como cambio climático o articulación de esfuerzos específicos de investigación e innovación tecnológica.
} 
La definición de las directrices medioambientales recae en el Consejo de Ministros para la Sustentabilidad, del cual forma parte el Ministerio de Agricultura junto a otros ministerios sectoriales.

Atendiendo al hecho de que las preocupaciones respecto del impacto sobre el medio ambiente de los procesos productivos, y a la realidad que desde ya impone el cambio climático, esta vinculación deberá ser aún más estrecha en el futuro inmediato, siendo necesario por tanto reforzar las capacidades técnicas del ministerio de agricultura para fortalecer este vínculo institucional.

\subsection{Ministerio de Obras Públicas.}

El ministerio de obras públicas es el responsable por la construcción de infraestructura, lo que desde luego tiene gran relevancia para la competitividad sectorial.

Uno de los aspectos donde la vinculación cobra mayor relevancia es en el referido a la construcción de obras de acumulación de aguas, como tranques y embalses de diverso tamaño, e igualmente en la construcción y mejoramiento de canales matrices. A ello se agrega, la construcción de sistemas de abastecimiento de agua potable para las comunidades rurales, también bajo la responsabilidad del MOP.

Recientemente ha cobrado importancia la evaluación y construcción de obras de desalinización de agua de mar, destinada a satisfacer consumo de agua potable y de riego para la agricultura, con especial énfasis en reducir la presión sobre acuíferos exigidos por la mayor demanda urbana, las sequías y la expansión de la agricultura intensiva.

La prioridad, así como la aprobación de la construcción de las obras publicas en riego y drenaje se decide en el Consejo de Ministros de Riego, que es presidido por el Ministro de Agricultura, y cuyo vice presidente es el Ministro de Obras Públicas. En dicho consejo del que además forman parte los Ministros de Hacienda, Economía y Desarrollo Social. Actúa como secretaría técnica la Comisión Nacional de Riego que depende del Ministerio de Agricultura.

La adaptación de la agricultura al cambio climático tiene como instrumento principal en el caso de Chile la disponibilidad y gestión de los recursos hídricos, de modo que esta articulación seguramente será aún más relevante en el futuro inmediato.

\subsection{Ministerio de Relaciones Exteriores.}

La inserción internacional de la agricultura chilena ha sido un factor determinante para su crecimiento en las últimas décadas. Ello ha sido posible, como se ha mencionado, gracias a la negociación de numerosos acuerdos comerciales con las principales economías del mundo, acuerdos en los que se ha privilegiado e acceso a la oferta chilena de alimentos. La conducción de dichas negociaciones ha estado en manos de la Dirección Económica del Ministerio de Relaciones Exteriores (MINREL), que durante las negociaciones comerciales estableció un consejo interministerial, del cual forma parte el Ministerio de Agricultura a través de ODEPA.

En paralelo con las negociaciones comerciales, se establecieron programas de promoción de exportaciones, ejecutados a través de PROCHILE, entidad dependiente de la dirección económica del MINREL. Para ello se estableció con cargo a recursos fiscales, el Fondo de Promoción de Exportaciones Agropecuarias, dirigido por un consejo público-privado, presidido por el subsecretario (viceministro) de agricultura y ejecutado a través de ProChile. 


\section{MARCO E INSTRUMENTOS LEGALES.}

Como se ha destacado, el MINAGRI posee una arquitectura institucional que se despliega tanto a nivel central como regional.

Junto a la estructura básica que contiene los equipos técnicos y administrativos de apoyo dependientes directamente de la conducción central ejercida por el Ministro y el Viceministro, las tareas del ministerio se organizan y ejecutan a partir de sus servicios dependientes, que cuentan con presupuesto y equipos técnicos descentralizados, con presencia a nivel central y regional.

Dichos servicios, si bien dependen del Ministro en el nombramiento de sus directores nacionales responsables y en el establecimiento de sus prioridades estratégicas y programáticas, disponen de autonomía para la asignación de sus recursos y ejecución operacional de sus acciones.

Los principales servicios, de acuerdo a su importancia para el cumplimiento de las funciones y prioridades ministeriales son los siguientes:

\subsection{Ministerio de Agricultura.}

El Ministerio de Agricultura es la institución del Estado encargada de fomentar, orientar y coordinar la actividad silvoagropecuaria del país. Dado el hecho de que los servicios dependientes poseen un mandato legal especifico, así como independencia presupuestaria, la estructura central del ministerio es relativamente pequeña, concentrando tareas de asesoría jurídica, apoyo legislativo, control presupuestario y coordinación de las secretarias regionales ministeriales.

De acuerdo al decreto ley 294 de 1960, "su acción estará encaminada, fundamentalmente, a obtener el aumento de la producción nacional, la conservación, protección y acrecentamiento de los recursos naturales renovables y el mejoramiento de las condiciones de nutrición del pueblo".

\section{Misión}

Avanzar hacia un sector agroalimentario y forestal competitivo, sustentable, innovador y moderno, comprometido socialmente con el desarrollo regional y rural.

\section{Historia}

El Ministerio de Agricultura, Industria y Colonización fue creado en 1924, mediante el DL № 43. Entre otras funciones, se le asignaron la protección de las industrias agrícolas, reglamentación de la caza y de la pesca, control de los yacimientos guaníferos, fomento del crédito agrícola y todo lo relacionado al ramo de colonización.

Posteriormente, en 1927, con el Decreto № 7.912, se modificó su nombre a Ministerio de Fomento, entre cuyas atribuciones estaban comprendidas las relativas al gobierno del sector agrícola.

Finalmente, el 1 de agosto de 1930, el Ministerio del Interior dictó el Decreto № 3.524, que creó el Ministerio de Agricultura, el que, desde ese momento, actuó como una Secretaría de Estado independiente, sobre la base del Departamento de Agricultura del Ministerio de Fomento. A esta nueva cartera 
se le asignó como misión propender al desarrollo y fomento de la producción agrícola y de la enseñanza de la agricultura. ${ }^{13}$

Fuente: www.minagri.gob.cl

\subsection{Instituto de Desarrollo Agropecuario.}

El Instituto de Desarrollo Agropecuario (INDAP), es un servicio dependiente del Ministerio de Agricultura, creado el 27 de noviembre de 1962, cuyo mandato está establecido por la Ley Orgánica 18.910, modificada por la Ley 19.213 en mayo de 1993. Es un servicio descentralizado que tiene por objeto: "Promover el desarrollo económico, social y tecnológico de los pequeños productores agrícolas y campesinos, con el fin de contribuir a elevar su capacidad empresarial, organizacional y comercial, su integración al proceso de desarrollo rural y optimizar al mismo tiempo el uso de los recursos productivos".

Bajo este mandato, se faculta a la institución para desarrollar una amplia gama de acciones relacionadas con el desarrollo productivo y rural y se define la condición de sus beneficiarios/as que pueden ser:

-Pequeño(a) Productor(a) Agrícola: Es la persona natural que explota una superficie no superior a las 12 Hectáreas de Riego Básico, ${ }^{14}$ cuyos activos no superen el equivalente a 3.500 Unidades de Fomento, ${ }^{15}$ que su ingreso provenga principalmente de la explotación agropecuaria, y que trabaje directamente la tierra, cualquiera sea su régimen de tenencia.

-Campesino/a: Campesino(a): Es la persona natural que habita y trabaja habitualmente en el campo, cuyos ingresos provengan fundamentalmente de la actividad silvoagropecuaria realizada en forma personal, cualquiera que sea la calidad jurídica en que la realice, siempre que sus condiciones económicas no sean superiores a las de un pequeño(a) productor(a) agrícola, y las personas que integran su familia.

\section{Misión}

Contribuir al desarrollo económico sostenible y a la valorización de la Agricultura Familiar Campesina y sus organizaciones, mediante una acción de fomento tendiente a fortalecer el capital humano, social, productivo, natural y cultural, de hombres, mujeres, jóvenes y pueblos originarios en los territorios.

\section{Historia}

Durante sus más de 50 años de funcionamiento, la institución ha desarrollado una amplia gama de acciones destinadas al desarrollo productivo y rural. INDAP está compuesto por 15 direcciones regionales más 127 agencias y oficinas de áreas, distribuidas a lo largo de Chile; y un nivel central, donde se ubican las autoridades nacionales y los encargados nacionales de las diferentes divisiones de trabajo y programas.

\footnotetext{
${ }^{13} \mathrm{En}$ al Anexo 1, se incluyen las disposiciones legales que regulan el funcionamiento del Ministerio de Agricultura y de sus principales organismos dependientes.

1412 has de riego básico, es una medida destinada a hacer comparable el valor y productividad potencial de las propiedades agrícolas en las diferentes regiones del país, estableciendo como referencia una propiedad en el valle central de Chile, con acceso a rego.

${ }^{15}$ Equivalente a aproximadamente US \$ 125.000
} 


\section{Objetivos}

- Apoyar el acceso de la Agricultura Familiar Campesina a un sistema de extensión y apoyo a la innovación que mejore sus capacidades y habilidades para desarrollar emprendimientos agrícolas y rurales, considerando las oportunidades y restricciones que señalan los mercados, los territorios y el medio ambiente.

- Facilitar el acceso de la Agricultura Familiar Campesina a programas de financiamiento (créditos e incentivos) adecuados a las necesidades de capital de trabajo e inversiones requeridos para potenciar la diversidad de emprendimientos económicos, individuales y asociativos.

- Ampliar y mejorar las condiciones de acceso de la Agricultura Familiar Campesina a los mercados locales regionales, nacionales e internacionales, promoviendo productos tradicionales y diferenciados de alta calidad y buscando un acercamiento entre el productor y el consumidor final.

- Fortalecer el desarrollo organizacional de la Agricultura Familiar Campesina para así contribuir al desarrollo de su actividad productiva y de su integración a los mercados, así como al fortalecimiento de su participación y posicionamiento como un actor relevante en la sociedad.

- Apoyar el desarrollo y fortalecimiento del capital social de la Agricultura Familiar Campesina, impulsando la cooperación entre productores, así como la constitución de redes y alianzas entre éstos y los actores públicos y privados, para canalizar nuevos recursos y competencias hacia el mundo rural.

Fuente: www.indap.gob.cl

\subsection{Servicio Agrícola y Ganadero.}

Es el organismo oficial del Estado de Chile, encargado de apoyar el desarrollo de la agricultura, los bosques y la ganadería, a través de la protección y mejoramiento de la salud de los animales y vegetales.

Para evitar la introducción desde el extranjero de enfermedades o plagas que puedan afectar a los animales o vegetales y dañar gravemente a la agricultura, se han establecido los Controles Fronterizos fito y zoos sanitarios. Dichos Controles funcionan en los puntos de entrada al país, ya sea por vía terrestre, aérea o marítima.

Respecto a la exportación de productos animales o vegetales, el SAG efectúa su certificación sanitaria, reconocida internacionalmente y condición básica para el comercio internacional.

EI SAG también realiza acciones para conservar y mejorar los recursos naturales renovables, que afectan la producción agrícola, ganadera y forestal, con atribuciones para el control de la contaminación de suelos y aguas de riego, conservación de la flora y fauna silvestre y mejorar el recurso suelo, con el fin de prevenir la erosión y mantener su productividad.

\section{Historia}

El Servicio Agrícola y Ganadero, SAG, tiene sus inicios en la Dirección General de Agricultura y Pesca del Ministerio de Agricultura, existente hasta 1967, transformado en esa fecha en el servicio especializado en protección de la sanidad animal y vegetal. 
El 28 de julio de 1967 la nueva Ley de Reforma Agraria, transformó a la Dirección General de Agricultura y Pesca del Ministerio de Agricultura, en una persona jurídica de derecho público denominada "Servicio Agrícola y Ganadero, SAG".

Fuente: www.sag.gob.cl

\subsection{Corporación Nacional Forestal.}

La Corporación Nacional Forestal (CONAF) es una corporación de derecho privado, dependiente del Ministerio de Agricultura, que nace de una modificación de los estatutos de la antigua Corporación de Reforestación mediante Decreto del 19 de abril de 1973, con el objetivo de "contribuir a la conservación, incremento manejo y aprovechamiento de los recursos forestales del país". 16

Cuenta con oficinas y agencias en todas las Regiones y Provincias del País, y administra un total de 100 Áreas Silvestres Protegidas del Estado, entre Reservas Nacionales, Parques Nacionales y Monumentos Naturales, que suman 14,56 millones de ha. y trabajan en ella más de 1.800 personas.

\section{Misión}

Contribuir al desarrollo del país a través del manejo sostenible de los ecosistemas forestales y de los componentes de la naturaleza asociados a éstos, la que se alcanzará mediante:

- El fomento, el establecimiento, restauración y manejo de los bosques y formaciones xerofíticas;

- El aumento del arbolado urbano;

- La mitigación y adaptación de los efectos del cambio climático;

- La fiscalización de la legislación forestal y ambiental;

- La protección de los recursos vegetacionales y la administración de las Áreas Silvestres Protegidas del Estado, para las actuales y futuras generaciones.

\section{Historia}

La fundación de CONAF es el resultado de un largo proceso durante el cual la el país fue tomando conciencia de la necesidad de conservar los recursos forestales y la vida silvestre impulsando su aprovechamiento racional.

Este proceso se inicia a comienzos del siglo XX y su primer hito importante es la creación de la Reserva Forestal de Malleco en 1907. Hechos posteriores, como la creación de otras Reservas Forestales y Parques Nacionales, la promulgación de la Ley de Bosques en 1931, el programa de desarrollo de la industria forestal -Corfo, los incentivos a la forestación, leyes de protección de especies del bosque chileno, entre otras acciones, culminaron durante la década de los 60 con la formulación del Programa Nacional de Reforestación, la creación de la División Forestal del SAG, el Departamento Forestal de Cora, el Programa Nacional de Prevención y Combate de los Incendios Forestales, la creación

\footnotetext{
${ }^{16}$ La fórmula jurídica adoptada para la creación de CONAF obedeció a la realidad política de la época, que bloqueaba la creación de nuevos entes públicos. A pesar de sucesivos intentos por normalizar su realidad jurídica convirtiéndola en un servicio público, hasta la fecha no ha sido posible materiazar este ajuste institucional y legal.
} 
de la Administración de Parques Nacionales y Reservas Forestales, y la creación el 13 de mayo de 1970 de la Corporación de Reforestación.

La conveniencia de aunar en una sola institución aquellas tareas dependientes del Ministerio de Agricultura, dio origen a la CONAF, en base a los estatutos de la Corporación de Reforestación.

Cabe destacar que CONAF ha sido responsable de algunas leyes que han sido y son esenciales para el sector, como instrumentos de conservación y uso sustentable de los recursos naturales de vocación forestal del país.

\section{Decreto Ley 701.}

Cuerpo Legal que nace el año 1974 con el objetivo de impulsar el desarrollo forestal de Chile; para este efecto se establecen incentivos a la actividad forestal:

-Bonificación para la forestación o estabilización de dunas en suelos de aptitud preferentemente forestal.

-Bonificación y beneficio tributarios para realizar actividades de administración y manejo de bosques plantados en terrenos de aptitud preferentemente forestal.

Posteriormente, en el año 1998 se dicta la ley № 19.561 que modifica el D.L. N. 701, a través del cual se incentiva la forestación de pequeños propietarios y de suelos frágiles y degradados y las prácticas de recuperación de suelos. Esta modificación legal incorpora dos tipos de incentivos:

-Bonificación a pequeños propietarios para realizar actividades de forestación y manejo de bosques plantados en suelos de aptitud preferentemente forestal.

-Bonificación para realizar actividades de forestación, recuperación de suelos y/o estabilización de dunas en suelos frágiles, ñadis o en proceso de desertificación, en suelos degradados, o en suelos degradados con pendientes superiores al $100 \%$.

El Decreto Ley cuenta con cuatro reglamentos que complementan los contenidos de este:

-Decreto Supremo N. 193, de 1998, del Ministerio de Agricultura. Reglamento general del Decreto Ley N. ${ }^{\circ} 701$, de 1974 .

-Decreto Supremo N.ํ 192, de 1998, del Ministerio de Agricultura. Reglamento Para el Pago de Bonificaciones Forestales.

-Decreto Supremo N. 1.341, de 1998, del Ministerio de Hacienda. Reglamento que establece normas contables aplicables a los contribuyentes que realizan actividades forestales de conformidad al Decreto Ley № 701, de 1974, sobre Fomento Forestal.

-Decreto Supremo N. 259, de 1980, del Ministerio de Agricultura. Reglamento técnico Decreto Ley N. 701 , de 1974.

Cabe señalar con fecha 31 de diciembre de 2012 expiró la vigencia del sistema de incentivos que contempla el artículo $12^{\circ}$ del Decreto Ley № 701, de 1974, razón por la cual las forestaciones y otras actividades bonificables que se realicen a partir del $1^{\circ}$ de enero de 2013 no serán susceptibles de bonificarse, de acuerdo a la normativa actualmente vigente. 


\section{Ley de Bosque Nativo}

La Ley N ${ }^{\circ} 20.283$, sobre Recuperación del Bosque Nativo y Fomento Forestal, define (en su Artículo $2^{\circ}$ ) al Bosque Nativo como al "bosque formado por especies autóctonas, provenientes de generación natural, regeneración natural, o plantación bajo dosel con las mismas especies existentes en el área de distribución original, que pueden tener presencia accidental de especies exóticas distribuidas al azar."

Con la promulgación de la Ley de Recuperación del Bosque Nativo y Fomento Forestal, Chile dispone de la más moderna legislación de Latinoamérica destinada al desarrollo sustentable de los recursos vegetacionales originarios. Esta normativa tiene como espíritu impulsar el progreso social y económico de las comunidades rurales en equilibrio con la protección del medio ambiente. ${ }^{17}$

Fuente: www.conaf.cl

\subsection{Oficina de Estudios y Políticas Agrarias.}

La Oficina de Estudios y Políticas Agrarias -ODEPA-, es un servicio público centralizado, dependiente del Presidente de la República a través del Ministerio de Agricultura, creada mediante la Ley № 19.147, que fuera publicada en el Diario Oficial del 21 de Julio de 1992.

ODEPA, según señala el Artículo $2^{\circ}$ de dicha Ley, tendrá por objeto proporcionar información regional, nacional e internacional para que los distintos agentes involucrados en la actividad silvoagropecuaria adopten sus decisiones.

Se le encomienda, además, apoyar la gestión del Ministerio de Agricultura a través de:

- Prestar servicios de información gratuitos de interés sobre la actividad agropecuaria, a través de publicaciones, estadísticas, informes, estudios, noticias, entre otros;

- Participar en la definición de criterios destinados a sustentar la posición negociadora del país en materia de comercio exterior sectorial, en coordinación con el Ministerio de Relaciones Exteriores u otros organismos públicos que cumplan funciones relacionadas.

- Colaborar en la coordinación de los programas de asistencia técnica y de cooperación internacional;

- Evaluar los proyectos presupuestarios de los servicios del sector, los que somete a la aprobación del Ministro y efectúa el seguimiento de su gestión programática y presupuestaria;

- Efectuar estudios de la realidad silvoagropecuaria, detectar los problemas y emergencias que la afectan, evaluar y proponer soluciones;

- Asesorar al ministro y al subsecretario en materias pertinentes;

\footnotetext{
${ }^{17}$ Se incluye texto de esta ley en el anexo 2 de este informe
} 


\section{Misión}

En el marco de lo que la Ley N 19.147 dispone, la misión institucional de ODEPA es "fortalecer la gestión del Ministerio de Agricultura y de los agentes públicos y privados involucrados en el ámbito silvoagropecuario, a través de la prestación de servicios especializados de asesoría e información”.

Cabe destacar que el año 1967 se creo la Oficina de Planificación Agrícola, con funciones de planificación sectorial, especialmente aquella dirigida al sector beneficiario de la reforma agraria, así como de administración de algunos de los instrumentos de política en boga en dicha época, dirigidos al establecimiento de precios mínimos y cuotas de importación entre otros.

El gobierno militar extinguió este servicio en los meses finales de su gestión en 1989. La recreación de ODEPA en 1992, si bien conserva la sigla cambia sustantivamente sus funciones, como se detalla en la ley incluida en el anexo 1 de este informe.

Fuente: www.odepa.gob.cl

\subsection{Comisión Nacional de Riego.}

Este servicio se creó en septiembre de 1975, y cuyo principal objetivo es asegurar el incremento y mejoramiento de la superficie regada del país. Desde 1985 administra la Ley №18.450 de Fomento a la Inversión Privada en Obras de Riego y Drenaje y, a través de sus concursos, aporta al desarrollo agrícola de los productores del país. ${ }^{18}$

Su estructura se organiza a partir de un Consejo de Ministros integrado por los titulares de Agricultura -quien lo preside-; Economía, Fomento y Turismo; Hacienda; Obras Públicas, y Desarrollo Social y Familia. Además, cuenta con una Secretaría Ejecutiva, cuya función principal es ejecutar los acuerdos que el Consejo adopte.

\section{Misión}

Dirigir la acción pública en materia de riego, mediante la realización de estudios, programas, proyectos e instrumentos de fomento tendientes a asegurar el incremento y mejora de la superficie en un marco sustentable, social, económico y ambiental.

\section{Objetivos}

- Contribuir a la formulación de la política de riego nacional.

- Mejorar la eficiencia del riego a través de proyectos de desarrollo y transformación productiva.

- Focalizar los esfuerzos hacia el desarrollo de regiones extremas del país y grupos de productores en situación vulnerable.

- Fomentar la inversión privada en obras de riego mediante la optimización de inversiones y asignación de subsidios en riego y drenaje.

\footnotetext{
${ }^{18}$ Los recursos de esta ley se han ido aumentando progresivamente, hasta superar los US \$100 millones anuales, y son una herramienta fundamental para promover la tecnificación del riego intrapredial, así como para desarrollar obras de mejoría en la infraestructura secundaria y terciaria de canales de regadío.
} 
- Evaluar la factibilidad técnica y económica de inversiones en obras rentables de riego de las cuencas hidrográficas del país.

\section{Ley de Fomento al Riego - Ley N¹8.450}

La Comisión Nacional de Riego a través del Departamento de Fomento al Riego y Drenaje administra la Ley №18.450 de Fomento a la Inversión en Obras de Riego y Drenaje, con el objetivo de aumentar el área de riego, mejorar el abastecimiento de agua en superficies regadas en forma deficitaria, mejorar la calidad y la eficiencia de la aplicación del agua de riego o habilitar suelos agrícolas de mal drenaje.

La Ley de Fomento al Riego y Drenaje №18.450 es un instrumento de fomento que, a través de un sistema de concursos, puede bonificar hasta un $90 \%$ del costo total del proyecto para acceder a infraestructura y sistemas de riego tecnificado, realizar nuevas construcciones y mejoramiento del sistema de conducción y distribución de aguas de riego y la construcción del proyecto de una obra de riego y/o drenaje. La bonificación se otorga a los proyectos aprobados y seleccionados en concurso y se hace efectiva una vez que el proyecto es construido.

Para postular tanto las personas naturales como jurídicas deben acreditar la titularidad de la tierra, la titularidad sobre los derechos de aguas y presentar un proyecto mediante un consultor de la Ley $N^{\circ} 18.450$.

Pueden presentar sus proyectos Organizaciones de Usuarios del Agua, constituidas y en proceso de constitución; personas naturales, que exploten un predio agrícola y personas jurídicas, cuyo objetivo sea la explotación agrícola. ${ }^{19}$

Fuente: www.cnr.gob.cl

\subsection{Instituto de Investigaciones Agropecuarias.}

El Instituto fue fundado en 1964, obteniendo personalidad jurídica mediante Decreto Supremo de Justicia $N . ⒈ 093$ de ese mismo año. Actualmente, cuenta con alrededor de 900 trabajadores especializados, de los cuales 33 directivos, 253 investigadores, 298 profesionales y técnicos de apoyo, y 289 operarios, que cumplen labores administrativas, de campo y laboratorio, para el desarrollo de la investigación, transferencia de tecnologías y extensión al servicio del sector agroalimentario de Chile.

Su oficina principal se ubica en Santiago y tiene presencia nacional desde Arica a Magallanes, a través de diez Centros Regionales de Investigación, diez Centros Experimentales, seis Oficinas Técnicas y laboratorios especializados en cada dependencia del Instituto.

Posee también una red de Bancos de Germoplasma, compuesta por un Banco Base y Activo de semillas y especies nativas localizado en Vicuña, Región de Coquimbo; cuatro Bancos Activos de cultivos, hortalizas, frutas, leguminosas y papas en Santiago, Chillán, Temuco y Osorno (regiones Metropolitana, del Biobío, La Araucanía y Los Lagos, respectivamente); y un Banco de Recursos Genéticos Microbianos, situado también en Chillán. Este último constituye un referente a nivel latinoamericano para la preservación ex situ de microorganismos.

\footnotetext{
${ }^{19}$ Se incluye el detalle de esta ley en el anexo 2 de este informe
} 
Además, el Instituto colabora en ocho Centros Tecnológicos CONICYT, de los cuales ha sido entidad fundadora y partícipe en sus proyectos. Cuenta también con alrededor de 150 estaciones meteorológicas automáticas que están adscritas a la Red Agroclimática Nacional del Ministerio de Agricultura de Chile.

Su estatuto jurídico corresponde al de una Corporación de Derecho Privado, dotada de autonomía para administrar su presupuesto y patrimonio. Su Director Nacional es designado por el ministro de agricultura y su órgano de dirección es un Consejo, presidido por el ministro de agricultura y compuesto por representantes del sector público, académicos y representantes del sector privado agrícola.

\section{Misión}

Generar y transferir conocimientos y tecnologías estratégicas a escala global, para producir innovación y mejorar la competitividad del sector agroalimentario.

Fuente: $\underline{w w w . i n i a . g o b . c l}$

\subsection{Centro de Información en Recursos Naturales.}

El Centro de Información de Recursos Naturales, CIREN, es un instituto tecnológico y servicio de apoyo del Ministerio de Agricultura, que proporciona información de valor de los recursos naturales renovables de Chile.

Corresponde a una institución con personalidad jurídica y de derecho privado que, por más 30 años, ha proporcionado información sobre los recursos naturales y productivos del país, mediante el uso de tecnologías y aplicaciones geoespaciales. El resultado del trabajo ha permitido construir la base de datos más importante relacionada a información georreferenciada de suelos, recursos hídricos, climas, Información frutícola y forestal que existen en Chile, además de un completo catastro de la propiedad rural.

CIREN trabaja para asegurar la calidad en la provisión de bienes públicos y en la generación de nuevos productos y servicios de alto valor, que contribuyan a la planificación, toma de decisiones y diseño de políticas de desarrollo productivo y de ordenamiento territorial.

Sumado a ello, la institución provee información actualizada sobre el territorio y sus recursos para mitigar los posibles riesgos a los que se enfrentan, entre los que se encuentran los desastres naturales y el cambio climático. El compromiso del centro es minimizar el impacto de estos eventos, manteniendo la calidad de vida y los medios de producción.

\section{Misión}

Aportar al desarrollo de la agricultura y al uso sustentable de recursos naturales del país, entregando información oportuna y de calidad, generada a través de diferentes plataformas tecnológicas que contribuyan a la planificación, toma de decisiones y diseño de políticas de desarrollo productivo y de ordenamiento territorial.

\section{Historia}

Tras el terremoto y tsunami de Valdivia en 1960, se dió inicio en Chile al proyecto Aero fotogramétrico OEA Chile BID, que generó una cubierta cartográfica sobre la base de mosaicos de fotografías aéreas de las zonas más afectadas. 
Así, en 1964 nace, bajo el alero de la Corporación de Fomento de la Producción (CORFO), el Instituto de Investigación de Recursos Naturales (IREN). Tras 21 años y gracias al progreso, un nuevo rol en la representación espacial y la integración de la información en el análisis territorial, el Instituto de Investigación de Recursos Naturales se convirtió en una corporación de derecho privado con un Consejo Directivo a la cabeza.

Ya en el año 2004, el Centro de Información de Recursos Naturales (CIREN) comenzó a tener una dependencia estratégica y técnica en el Ministerio de Agricultura con apoyo directo en el trabajo de gestión agrícola, información para la toma de decisiones y focalización de sus instrumentos.

Fuente: www.ciren.cl

\subsection{Instituto Forestal.}

El Instituto Forestal (INFOR) es un Instituto Tecnológico de Investigación del Estado de Chile, adscrito al Ministerio de Agricultura. Nace en el año 1961 como Proyecto de FAO y es creado oficialmente por el Gobierno de Chile en el año 1965.

INFOR está constituido como una corporación de derecho privado, adscrita al Ministerio de Agricultura, es administrado y dirigido por un Director Ejecutivo, nominado por un Consejo Directivo. Este Consejo es de siete miembros que a su vez son nominados por la Vicepresidencia de la Corporación de Fomento de la Producción, el Ministerio de Agricultura, el Instituto de Desarrollo Agropecuario y la Corporación Nacional Forestal.

La institución cuenta con cinco Sedes: Diaguitas en La Serena, Metropolitana en Santiago, Bio Bio en Concepción, Valdivia en Valdivia y Patagonia en Coyhaique.

\section{Misión}

Contribuir al desarrollo forestal chileno, fomentando el uso sustentable de los ecosistemas forestales para el beneficio de la sociedad, a través de la creación y transferencia de conocimientos, de productos y servicios innovadores de excelencia, y de información forestal relevante y oportuna para la toma de decisiones.

\section{Historia}

El Instituto Forestal realiza investigación forestal en el país desde su nacimiento como Proyecto FAO en el año 1961 y su creación oficial por el Gobierno de Chile en el año 1965. Innumerables investigaciones han sido desarrolladas desde entonces y la institución ha sido pionera en el sector forestal en una variedad y cantidad de investigaciones e innovaciones y tecnologías.

Destacan por ejemplo la introducción al país de la motosierra y el tractor articulado, la realización de los primeros inventarios nacionales en bosques nativos y la tipificación de estos recursos en la década de los 60 . Algo después fueron los inventarios, la elaboración de los índices de sitio, el desarrollo de tablas de volúmenes y posteriormente los modelos de simulación de crecimiento y rendimiento en plantaciones de pino radiata, inicialmente, y de eucalipto y otras especies más recientemente. 
En la actualidad sus labores de investigación, articuladas con el sector privado, se focalizan en el análisis de las condiciones y usos específicos de las maderas obtenidas de los bosques nativos e introducidos, así como la investigación acerca de nuevos usos de la madera.

Fuente: www.infor.cl

\subsection{Fundación para la Innovación Agraria.}

El 15 de diciembre de 1981 el Ministerio de Justicia crea el Fondo de Investigación Agropecuaria, con el objetivo de promocionar y fomentar la investigación agrícola, pecuaria, forestal y acuícola a través del financiamiento total o parcial de proyectos de investigación; para promover la transformación de la agricultura y de la economía rural.

Sobre la base jurídica inicial de este fondo, el Ministerio de Agricultura concibió una institucionalidad que apoyara la innovación agraria en Chile.

Luego de una modificación a sus estatutos se creó la Fundación para la Innovación Agraria, FIA, publicados en el diario oficial el 16 de noviembre de 1996.

Gracias al desarrollo de algunos programas y proyectos, FIA ha contribuido al surgimiento de rubros como el olivícola, de ovejas lecheras, frutales de nuez como el avellano europeo, pistacho y macadamia. También destacan, los bulbos de flores, o la valorización económica de las cepas tradicionales de viñedos de larga presencia en el país.

Otra de las áreas de trabajo ha estado vinculada a la elaboración y publicación de estudios prospectivos que establecen los lineamientos futuros para el sector silvícola Y agroalimentario; para responder a los desafíos que enfrenta la agricultura a través de la innovación con una mirada a largo plazo.

El trabajo de la fundación se complementa con la acción del instituto de investigaciones agropecuarias, INIA, y dada su mayor flexibilidad institucional y reglamentaria, se ha transformado en un buen vehículo para estimular innovación tecnológica y productiva, subsidiando parcialmente aquellos proyectos que por su alto nivel de incertidumbre y riesgo no es posible llevar adelante con el solo esfuerzo privado. $^{20}$

La evolución del fundamento legal y estructura institucional que determina el funcionamiento del Ministerio de Agricultura de Chile, permite reflexionar acerca de algunas de sus características y organización que pueden ser de utilidad para otras experiencias de construcción institucional. ${ }^{21}$

\footnotetext{
${ }^{20}$ La flexibilidad que le otorga el hecho de ser una Fundación, le permite recibir y transferir recursos públicos y privados para cofinanciar proyectos de innovación tecnológica en fases precompetitivas.

${ }^{21}$ La Fundación para la Innovación Agraria es dirigida por un Consejo, presidido por el Ministro de Agricultura, con participación publica y privada.
} 


\section{CONSTRUCCION INSTITUCIONAL: ALGUNAS LECCIONES.}

La experiencia de Chile, similar en varios aspectos a la de otros países de la región, permite reflexionar acerca de algunas de las condiciones que deberían caracterizar los esfuerzos de construcción institucional, particularmente en situaciones de transición entre regímenes políticos, lo que suele abrir por periodos limitados de tiempo espacio para restructuraciones de mayor envergadura.

\subsection{Flexibilidad legal y capacidad adaptativa.}

Una constatación común a prácticamente toda estructura institucional, pública o privada, es la inercia que se establece una vez definidos los marcos legales, lo que por lo general dificulta seriamente sus posibilidades de ajuste y renovación. Frecuentemente, las culturas institucionales y la consolidación de intereses corporativos hacen difíciles los procesos de reforma institucional.

El establecimiento, en los textos legales de origen, de mecanismos que faciliten ajustes posteriores parece ser una condición necesaria, más aún en situaciones de transición social y política. La justificación para ello es visible si se consideran los rápidos cambios en el escenario global, como es justamente la evidencia en estos días.

\subsection{Funcionalidad a estrategia y objetivos de desarrollo sectorial.}

La construcción institucional no opera en un vacío social y económico, de manera que tanto el marco legal como la estructura institucional debe ser funcional a los objetivos y definiciones estratégicas de largo plazo establecidas por las autoridades políticas.

Justamente porque esas orientaciones estratégicas pueden sufrir cambios y ajustes atendiendo a la realidad nacional o al escenario externo, es recomendable una construcción institucional dotada de flexibilidad y capacidades de ajuste adaptativo.

El caso de Chile muestra como las prioridades de la agenda para el sector agroalimentaria fueron cambiando a lo largo del tiempo, y ellas usualmente, aunque con retardo, requirieron de ajustes en la institucionalidad y organización del trabajo ministerial.

En el caso de Venezuela, los informes de IFPRI/MSU muestran claramente que el país tiene que prepararse para un papel diferente del sector agropecuario en la estrategia de desarrollo. Ciertamente, desde el descubrimiento del petróleo a principios del siglo XX en Venezuela, el desarrollo económico en general de ese país, y el desempeño de su sector agropecuario, se vio marcado por la evolución de los mercados globales de energía y su correlato con el funcionamiento nacional de la actividad petrolera. El sector agropecuario fue perdiendo incidencia en el PBI, y su desarrollo estuvo marcado por la Enfermedad Holandesa (con la apreciación del tipo de cambio) y la dependencia de subsidios del Estado y protección comercial. El contexto actual será muy diferente, no solamente por el colapso de la producción petrolera venezolana, sino porque los cambios tecnológicos en energía y el desafío del cambio climático ponen límites muy claros a una estrategia de desarrollo basada en el petróleo. 
Por ende, la evolución del sector estará basada en un marco diferente de la protección comercial y subsidios distorsionantes. Más bien requerirá, como en el caso de Chile y otros países que han seguido caminos similares, más inversiones en los fundamentos de la competitividad (como ciencia y tecnología, infraestructura, capital humano y aspectos similares) dentro de una economía más abierta al comercio internacional, y con un esquema macroeconómico con un tipo de cambio más competitivo para productos comercializables internacionalmente.

La crisis sanitaria que afecta al mundo hará aún más urgentes las necesidades de redefinición estratégica y ajuste institucional del sector agropecuario, revalorizando el rol de la agricultura como productora de alimentos componente esencial para mejorar la salud, como sector intensivo en mano de obra para absorber empleo y como eje clave para la articulación de políticas de combate a la pobreza rural.

\subsection{Articulación con institucionalidad pública de apoyo.}

La mayor complejidad de los sistemas alimentarios establece necesidades de coordinación con numerosas agencias y entidades públicas dependientes de otros ministerios y organismos del Estado. Por ello, establecer mecanismos formales de decisión, con participación en las decisiones de los ministerios y agencias involucradas es especialmente importante. En el caso de Chile, los Consejos interministeriales de riego, y de sustentabilidad son ejemplos interesantes de analizar. Algo similar puede señalarse respecto al consejo directivo de CORFO, con marcada importancia para el desarrollo del sector agroalimentario.

Un tema relacionado es la articulación con la política macroeconómica y la de comercio internacional, donde, como ya se enfatizó y se reitera algo más adelante, el papel de ODEPA ha sido central.

Con la expansión de los objetivos esperados del sector agropecuario a toda una serie de temas económicos, sociales, de medio ambiente, y de salud y nutrición, y la ampliación del marco de análisis al concepto de "sistema alimentario," siempre está presente la discusión de dónde definir los límites de la institucionalidad "agropecuaria" (Díaz-Bonilla, 2015). Por ejemplo, ¿la agroindustria es parte del Ministerio de Agricultura o del de Industria? ¿Cómo articular medio ambiente con la producción agropecuaria? ¿Qué parte de las tareas relacionadas con seguridad alimentaria y calidad nutricional deberían estar en el Ministerio de Agricultura, y cuáles son responsabilidad de los Ministerios de Salud? En la sección siguiente se toma una visión más centrada en las tareas tradicionales de los Ministerios de Agricultura, reconociendo que cualquier esquema institucional que se elija va a requerir mecanismos de coordinación en la dirección de los otros temas mencionados recién.

Independientemente de los arreglos institucionales específicos, se hace necesario adoptar una visión de institucionalidad ampliada, que va más allá de los límites de los ministerios de agricultura. Inclusive, será también recomendable incluir mecanismos que permitan una interacción ágil entre las agencias públicas y lo que podría ser definido como un sector para estatal, ONG s, fundaciones, organizaciones de la sociedad civil, etc., en capacidad de producir bienes públicos, como transferencia tecnológica, investigación, apoyo a la gestión económica, etc., que complementen el esfuerzo estatal.

Otro aspecto importante de la institucionalidad chilena es que las entidades creadas tienen funciones claras, y disponen de los instrumentos de políticas necesarios para llevar adelante sus funciones. En 
muchos casos en los países en desarrollo y en nuestra región, las instituciones creadas tienen sus presupuestos orientados fundamentalmente a pagar salarios, sin los instrumentos legales y presupuestarios para generar los bienes y servicios específicos que hacen a su función. ${ }^{22}$

\subsection{Organización funcional.}

La identificación de las principales funciones que debe cumplir un Ministerio de Agricultura como responsable del fomento del desarrollo y del gobierno sectorial deberá reflejarse en el tipo de organización a establecer. Sin perjuicio de que cada realidad nacional posee demandas específicas, hay un conjunto de tareas comunes a la mayor parte de las experiencias de desarrollo de sector agroalimentario para las cuales se requiere alguna forma especializada de organización institucional. Cabe hacer presente que en diversos países se incluye bajo la dependencia de los ministerios de agricultura las áreas de pesca y de desarrollo forestal, para lo cual ciertamente se requiere una línea especializada de organización y servicios, frecuentemente determinadas a través de viceministerios y subsecretarias.

\section{Formulación de políticas y análisis económico.}

La experiencia chilena, con el establecimiento de ODEPA como ente especializado en la formulación de políticas, provisión de información especializada a los agentes públicos y privados y análisis económico de sector, ha sido de gran relevancia para la gestión del ministerio en apoyo al desarrollo sectorial. Se ha transformado en el órgano de apoyo técnico especializado, de soporte a la gestión de las autoridades ministeriales en áreas tales como la realización de estudios, generación de información especializada, negociación de acuerdos comerciales internacionales, programación y gestión presupuestaria y el vínculo con el área económica del gobierno.

Existen experiencias similares, como es el caso de la OPIPA en Uruguay y de áreas especializadas bajo otras formas institucionales como en Perú y Colombia. En todas ellas este tipo de apoyo técnico es altamente valorado.

\section{Sanidad vegetal y animal.}

La promoción y resguardo de la salud vegetal y animal es una función indispensable en la organización de un ministerio de agricultura. La experiencia más común como ocurre en la mayor parte de los países de la región ( Chile, Argentina, Perú, Ecuador, Colombia y Uruguay entre otros) es la conformación de un servicio público especializado, responsable por: i) Promoción de los estándares de salud animal y vegetal, controlando plagas y enfermedades que afectan la producción, el comercio e incluso la salud humana; ii) Protección en frontera, impidiendo el acceso de plagas y enfermedades; iii) Diálogo con sus contrapartes técnicas de países con los cuales se mantienen relaciones comerciales, para el establecimiento de protocolos de ingreso y egreso de productos agropecuarios. En diversas experiencias, se suele encargar igualmente a los servicios de sanidad animal y vegetal el desarrollo y control de los sistemas de trazabilidad e incluso de inocuidad de los alimentos.

\footnotetext{
${ }^{22}$ Un buen ejemplo de ello es el caso de INDAP, que concentra en torno al 50\% del presupuesto global del ministerio, con recursos para transferencia tecnológica, crédito y apoyo a la comercialización, instrumentos dirigidos al apoyo a la pequeña agricultura. En términos similares puede visualizarse el presupuesto de la Comisión Nacional de Riego y del SAG, orientados a la producción de los bienes públicos que su mandato legal determina.
} 
Una parte importante del diseño institucional es la decisión sobre el alcance de la participación del sector privado: su compromiso es fundamental para asegurar el cumplimiento de las regulaciones sanitarias y fitosanitarias; pero, por otra parte, la tarea de estos órganos del gobierno es la supervisión del sector privado, y por ende deben mantener su independencia regulatoria y de control.

\section{Investigación y transferencia tecnológica.}

La generación y adaptación de tecnología es otra función necesaria para la economía sectorial, mas aun en un periodo de rápidos cambios tecnológicos que afectan la productividad y competitividad de la agricultura, a lo que se agregan los requerimientos para construir sistemas agroalimentarios resilientes y con capacidad de adaptación al cambio climático. Las tareas de asistencia técnica pueden o no estar asociadas en un único modelo institucional, y en todo caso deben tener mecanismos claros de retroalimentación desde los productores y sus asociaciones, así como otros sectores vinculados a temas de ciencia y tecnología.

Existen diversos modelos organizacionales para los institutos de investigación agropecuaria, públicos, publico-privados y dotados de mayor o menor autonomía. Sin perjuicio de ello, debe asegurarse una clara articulación con las autoridades ministeriales que determinan la estrategia de desarrollo sectorial, y con el sector privado que identifica en el terreno las demandas tecnológicas de respaldo al proceso productivo.

\section{Apoyo a la agricultura familiar y pequeña agricultura.}

La heterogeneidad estructural de la agricultura, con una proporción muy importante de pequeños productores, plantea la necesidad de establecer políticas e instrumentos de apoyo específicos, que respalden su producción primaria, su modernización tecnológica y su acceso a los mercados.

A este respecto, igualmente existen diversos modelos en la región, tanto en relación a la amplitud de cobertura que se les asigna, así como a sus modalidades de operación. Igualmente, puede o no estar incorporada la tarea de servir como agente financiero especializado para la pequeña agricultura, como es el caso del INDAP en Chile, tanto para asegurar el flujo de capital de operaciones como el de inversión, frecuentemente orientados a la modernización y transformación productiva.

En años recientes, se ha incluido como un tipo de demanda prioritaria a atender el apoyo a la organización de la agricultura familiar, sea bajo la forma de cooperativas u otras modalidades afines, con la finalidad de favorecer su inserción en los circuitos comerciales más dinámicos.

\section{Riego y drenaje.}

Los modelos institucionales a este respecto son igualmente diversos, y pueden o no estar establecidos dentro de la estructura institucional de los ministerios de agricultura. Sin embargo, el hecho de que la agricultura es el principal usuario de los recursos hídricos, y de que estos son a su vez el principal instrumento para incrementar la productividad y propiciar la adaptación al cambio climático, sugieren la necesidad de disponer de equipos y estructuras especializadas dependientes o en todo caso estrechamente ligadas a los ministerios de agricultura.

Existen un conjunto de funciones asociadas al desarrollo de una agricultura moderna que pueden asumir formas diversas de organización institucional, tanto dentro del armado básico existente como 
dando lugar a estructuras institucionales más livianas y específicas. Es el caso entre otros del establecimiento de mecanismos de seguro agrícola, de manejo de stocks y bolsas de productos, de comunicaciones

\section{Financiamiento.}

El financiamiento de la agricultura requiere atender sus particulares característicos en términos de ciclos productivos, riesgo asociado y disponibilidad de garantías apropiadas a inversiones de mayor envergadura. Ello ha motivado al establecimiento en diversas latitudes de Bancos Agrarios especializados en al financiamiento a la agricultura. Es el caso de Ecuador, Perú en la región, y de numerosas otras experiencias en Europa y Asia.

En el caso de Chile, un actor importante es CORFO, que es un modelo diferente del basado en bancos, tanto por el fondeo como por sus operaciones. Así, ha puesto en marcha mecanismos orientado a proveer de garantías que hagan mas atractiva y menos riesgosas las operaciones de la banca con la pequeña y mediana empresa agrícola.

En el caso de Venezuela se está discutiendo la necesidad de un banco de segundo piso para la agricultura. Este esquema tiene sus ventajas y desventajas como lo demuestra la experiencia de varios países en la región (Díaz-Bonilla et al, 2019). Los bancos tradicionales de primer piso son vulnerables a captura y presión política para asignar crédito y hacer cumplir compromisos de pago. Pero los bancos de segundo piso pueden ser capturados por bancos comerciales, y no necesariamente llegan a los productores más necesitados con el crédito adecuado (dado el sesgo urbano y hacia empresas más grandes de los bancos privados).

Al margen de si los bancos dedicados al sector agropecuario son de primer o segundo piso, la discusión principal es su fondeo. FIRA en México, por ejemplo, un mecanismo de segundo piso, tiene una amplia fuente de recursos, lo que hace a esa institución muy relevante, al margen de si es de primer o segundo piso.

Además, la banca pública (de primer o segundo piso) tiene el problema de cómo combinar los aspectos de fomento al desarrollo y de sustentabilidad comercial. El tema central es diseñar bancos sectoriales que atiendan fallas de mercado (complementarios del sistema privado) y ayuden a mejorar las políticas públicas, con fondeo trasparente e incentivos para buena gestión, y sujetos a regulación y supervisión bancarias (Díaz-Bonilla et al, 2019)

Más allá de la modalidad que se adopte en cada país, la necesidad de disponer de un canal de financiamiento apropiado para la agricultura y ganadería, en condiciones que se ajusten a las características del sector parece una condición indispensable para estimular su crecimiento y desarrollo.

Un tema relacionado es la utilización de Fondos Parafiscales con usos específicos formados con aportes de los productores para actividades de apoyo al sector. En América Latina hay varios ejemplos, uno de los más notorios es el de Colombia, donde existen varios que financian diferentes actividades relacionadas con los productores, aunque no parecen incluir el crédito (o la provisión de garantías), y más bien se orientan hacia investigación agropecuaria extensión, extensión, y desarrollo de infraestructura (Díaz-Bonilla, et al, 2019). El funcionamiento de estos fondos depende de la solidez organizacional y la calidad de gobernanza de las cadenas productivas en las que participan los productores que hacen los aportes. 


\subsection{Organización territorial.}

El sector agropecuario y forestal se caracteriza por una muy amplia cobertura geográfica y territorial, lo que igualmente demanda disponer de canales y mecanismos que aseguren la presencia del ministerio y sus instituciones a nivel local, y al mismo tiempo que garanticen la coherencia en su accionar a nivel de campo.

En el caso de Chile, se optó por un tipo de organización con algunos componentes mixtos, que combinan dependencia desde el Ministerio de Agricultura de manera conjunta con la dependencia de las autoridades regionales y locales.

Como se visualiza en el organigrama, presentado en el capítulo 3 de este informe, los Secretarios Regionales Ministeriales, dependen del nivel central a través de la subsecretaria de agricultura y tiene por función coordinar el trabajo de las diferentes agencias del ministerio con presencia en la región, y al mismo tiempo formar parte del Gabinete Regional, presidido por el jefe de gobierno regional, autoridad nombrada por la Presidencia de la Republica.

Por otra parte, existen servicios dependientes del Ministerio de Agricultura, como es el caso de INDAP, SAG y CONAF que tienen oficinas a nivel regional e incluso provincial y comunal, justamente para asegurar su presencia y efectividad de sus servicios a nivel local.

\subsection{Cadenas Productivas}

Un aspecto relevante en la conducción y gobernanza sectorial es la estructuración y formalización de cadenas productivas con capacidad de interlocución y diálogo con el Ministerio de Agricultura. Las principales cadenas productivas, como las de granos, carne y lácteos entre otras, se reúnen con regularidad al alero del ministerio, siendo ODEPA la entidad responsable para oficiar como secretaría técnica y correa transmisora de requerimientos y propuestas hacia las autoridades superiores del ministerio.

Se trata de un modelo bien evaluado tanto por los agentes públicos como por los privados, pues contribuye a articular intereses entre los diferentes segmentos de la cadena, a definir objetivos comunes y en algunos casos a facilitar el flujo de servicios y bienes públicos básicos, como los sanitarios, de trazabilidad e inocuidad entre otros.

Es importante contar con una agenda de trabajo formalizada, y con análisis específicos de los temas en consideración, para evitar que las reuniones se conviertan en meras formalidades. 


\section{BIBLIOGRAFÍA}

Biblioteca del Congreso Nacional. Textos de leyes y reglamentos. www.bcn.cl

Díaz-Bonilla, Eugenio. 2015. Macroeconomics, agriculture, and food security: A guide to policy analysis in developing countries. Washington, D.C.: International Food Policy Research Institute (IFPRI). http://dx.doi.org/10.2499/9780896298590

Diaz-Bonilla, Eugenio; Fernandez-Arias, Eduardo; Piñeiro, Valeria; Prato, Bettina; and Arias, Joaquin. 2019. Foro de análisis financiamiento e inclusión financiera para el desarrollo agropecuario, rural y de sistemas alimentarios en América Latina y el Caribe: Documento resumen. LAC Working Paper 5. Washington, DC: International Food Policy Research Institute (IFPRI). https://doi.org/10.2499/p15738coll2.133448

Fundación para la Innovación Agraria. 2017. Memoria institucional. Dic 2017.

Instituto de desarrollo agropecuario. 2018. Memoria institucional. Enero 2018.

ODEPA. 2018. Panorama de la agricultura chilena. Ministerio de Agricultura

ODEPA. 2019. Panorama de la agricultura chilena. Ministerio de Agricultura.

ODEPA. Base de datos estadísticos de la agricultura chilena. www.odepa.cl

Ministerio de Agricultura. Una política de estado para la agricultura chilena: Periodo 2000-2010. Santiago 2000

Ministerio de Relaciones exteriores: Chile 20 años de negociaciones comerciales. Santiago, 2010.

Servicio agrícola y ganadero. Memoria institucional. Dic 2017.

\section{SOBRE EL AUTOR}

El Dr. Carlos Furche ha sido Director de la División de Desarrollo Económico de FAO (2018-2019), Ministro de Agricultura de Chile (2014-2018), Director General de Relaciones Económicas Internacionales del Ministerio de Relaciones Exteriores de Chile (2004-2010), y Director Nacional de la Oficina de Estudios y Políticas Agrarias (ODEPA) del Ministerio de Agricultura de Chile (1994-2004) y Consultor del BID, Banco Mundial, OEA, CEPAL, IFPRI y otros organismos internacionales y gobiernos.

\section{RECONOCIMIENTOS}

Agradezco el apoyo y dedicación de la Sra María Loreto Mery, ex secretaria ejecutiva de la Comisión Nacional de Riego del Ministerio de Agricultura de Chile por su dedicado apoyo en la búsqueda y sistematización de información sectorial básica así como de la historia institucional del ministerio 
Funding for this work was provided by the collaborative work with Michigan State University, financed by USAID. This publication has not been independently peer reviewed. Any opinions expressed here belong to the author(s) and are not necessarily representative of or endorsed by IFPRI.

\section{INTERNATIONAL FOOD POLICY RESEARCH INSTITUTE}

A world free of hunger and malnutrition

IFPRI is a CGIAR Research Center 